\title{
Contribution of multiple climatic variables and human activities to streamflow changes across China
}

Jianyu Liu, Qiang Zhang, Vijay P. Singh, Peijun Shi

\section{Corresponding author:}

Qiang Zhang, Ph.D., Professor, Editor of HP and HSJ, Humboldt Fellow

Key Laboratory of Environmental Change and Natural Disaster,

State Key Laboratory of Earth Surface Processes and Resource Ecology,

Academy of Disaster Reduction and Emergency Management,

Beijing Normal University,

Beijing 100875, China.

E-mail: zhangq68@bnu.edu.cn 


\section{Contribution of multiple climatic variables and human activities to}

$$
\text { streamflow changes across China }
$$

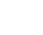

Jianyu Liu ${ }^{1}$, Qiang Zhang ${ }^{2,3,4}$, Vijay P. Singh ${ }^{5}$, Peijun $\mathrm{Shi}^{2,3,4}$

1. Department of Water Resources and Environment, Sun Yat-sen University, Guangzhou 510275, China;

2. Key Laboratory of Environmental Change and Natural Disaster, Ministry of Education, Beijing Normal University, Beijing 100875, China;

3. State Key Laboratory of Earth Surface Processes and Resource Ecology, Beijing Normal University, Beijing 100875, China;

4. Academy of Disaster Reduction and Emergency Management, Beijing Normal 2 University, Beijing 100875, China;

5. Department of Biological and Agricultural Engineering and Zachry Department of Civil Engineering, Texas A\&M University, College Station, Texas, USA; 5

Abstract: Using monthly streamflow data from the $1960-2000$ period and annual streamflow data from the 2001-2014 period, and also meteorological data from the 1960-2014 period from 815 meteorological stations across China, the Budyko-based hydrothermal balance model was used to quantitatively evaluate the fractional contributions of climate change and human activities to streamflow changes in ten 1 river basins across China. Particular importance was attached to human activities, 2 such as population density and Gross Domestic Product (GDP), and also water 3 reservoirs in terms of their relationship with streamflow changes. Results indicated that: (1) streamflow changes of river basins in northern China were more sensitive to 
climate change than those of river basins in southern China. Based on the degree of sensitivity, the influencing factors to which streamflow changes are sensitive included: precipitation $>$ human activities $>$ relative humidity $>$ solar radiation $>$ maximum temperature $>$ wind speed $>$ minimum temperature. Hence, it can be argued that hydrological systems in northern China are more fragile and more sensitive to changing environment than those in southern China and hence water resources management in northern China is more challenging; (2) during 1980-2000, climate change tended to increase streamflow changes across China and have a dominant role in streamflow variation. However, climate change tends to decrease streamflow in river basins of northern China. Generally, human activities cause a decrease of streamflow across China; (3) In recent years such as a period of 2001-2014, human activities tend to have increasing or enhancing impacts on instream flow changes, and fractional contributions of climate change and human activities to streamflow changes are, respectively, $53.5 \%$ and $46.5 \%$. Increasing human-induced impacts on streamflow changes have the potential to add more uncertainty in the management of water resources at different spatial and temporal scales. (1)

Key words: Fluvial hydrological processes; Budyko framework; Elasticity coefficients; Climate changes; Human activities

\section{Introduction}

6 Streamflow is one of the critical components of the hydrological cycle and is the key

7 to the understanding of influences of climatic change on water resources at regional and global scales (Arnell, 1999). Therefore, understanding of streamflow generation, 
variation and underlying causes in a changing environment is critical for the effective management of water resources (Burn, 1994; Arnell, 1999; Zhang et al., 2009, 2016). In general, environmental changes can be classified into two categories: climate-driven and human-driven (Xu, 2011; Wang et al., 2012). Climate change, combined with human activities, triggers remarkable changes in fluvial hydrological processes and these hydrological changes have caused numerous water resource problems across the globe (Barnett et al., 2008; Huang et al., 2013; Tan and Gan, 2015). However, instream flow changes are usually affected by the combination of climatic change, such as precipitation change and evapotranspiration change, and human activities, such as irrigation and building of water reservoirs in many regions of the world (e.g. Wang and Hejazi, 2011; Tan and Gan, 2015; Zhang et al., 2015). Therefore, quantification of the fractional contributions of climatic change and human activities to the instream flow changes is a crucial issue in hydrology. Besides, analysis of fluvial hydrological response to climate variability and human-induced land use and land cover changes is fundamental for understanding watershed hydrology and improving water resources and land management practices (e.g. Xu et al., 2014).

Numerous studies have reported in recent years, quantitatively differentiating the fractional contributions of climatic change and human activities or both to streamflow changes. Taking Minjiang, Fujian province, China, as a case study, Hu et al. (2014) discussed the impact of forest coverage change and its impacts on streamflow changes. Using long-term observational data from 16 meteorological 
stations and 2 hydrological stations from the period between the 1950s and 2010, Fan and He (2015) analyzed temperature and precipitation variability and its effects on streamflow in the upstream region of the Lancang-Mekong River (LMR) and Nu-Salween River (NSR). Some studies focused on specific human activities, such as dams or specific component of climatic changes, such as precipitation changes, showing the potential influence of these factors on streamflow changes. Zhao et al. (2012) evaluated the spatiotemporal patterns of dam-induced hydrologic alteration and precipitation variability in the Lancang River basin of southwest China from 1957 to 2000 with the linear regression method, the Mann-Kendall test, and the Range of Variability Approach (RVA). They indicated that the hydrologic regimes of the Lancang River during the 1957-2000 period were affected by damming and precipitation variability, but the hydrologic alteration was relatively low in the upstream areas of the river without a dam (Zhao et al., 2012). Nevertheless, components of climatic change have attracted more concern in the analysis of factors influencing streamflow changes (e.g. Gardner, 2009).

Some investigations addressed the combined influence of climatic change and human activities on streamflow variation. Li et al. (2007) evaluated the impact of climatic change (precipitation and potential evaporation) and human activities (soil conservation) on streamflow changes in the Wuding River basin in China. Bao et al. (2012) used the Variable Infiltration Capacity (VIC) model to model human activities (land use changes) and climatic change on streamflow changes of the Haihe River basin, quantifying the fractional contribution of human activities and climatic change 

human activities on streamflow changes, and different methods used, conclusions or

114 viewpoints can be sometimes different, which may lead to misunderstanding of 
hydrological processes and related underlying causes. This study therefore attempts to analyze monthly streamflow data from more than 300 hydrological stations and daily meteorological data from more than 800 meteorological stations from 10 river basins across China, evaluate the combined impacts of LUCC and climate change on streamflow changes with consideration of as many driving factors as possible with the aim to present a relatively complete picture of hydrological processes across China and related potential driving factors. In fact, attribution analysis of the streamflow change across China has been done. Yang et al. (2014) evaluated the contribution of climate change (precipitation and evaporation) to streamflow changes for 210 catchments across China. Huang et al. (2016) quantified impacts of five climatic variables, i.e., precipitation, net radiation, temperature, wind, and relative humidity, on annual streamflow changes for 207 catchments in China. In very recent study, Wang et al. (2016) quantified contribution of climatic changes such as five evaporation-related elasticities and also catchment alteration elasticity based on Budyko framework at seven large river basins across China. However, previous studies did not consider more influencing factors such as population density, GDP and also water storage capacity of water reservoirs, and these factors are also critical in alteration of hydrological processes besides land use and land cover (e.g. Wang et al, 2016). Meanwhile, due to pretty complicated spatial patterns of influencing factors for streamflow changes, hydrological data from more stations can further enhance human understanding of streamflow responses to external influencing factors when compared to previous studies with hydrological data from fewer stations (e.g. Yang et al., 2014; 
147 fractional contributions of six climatic variables, i.e., maximum temperature,

Huang et al., 2016; Wang et al., 2016). In this sense, this study can help to present a more complete picture showing impacts of more influencing factors than previous studies considered on streamflow changes at finer spatial scale. What's more, this study includes hydrological changes in very recent years, i.e. 2001-2014, and this point further highlights impacts of intensifying human activities and changing climate on streamflow changes since that climate is changing and human activities are intensifying. Analyses focused on time interval before 2000 only does not fully reflect impacts of climate changes and human activities on streamflow changes in recent years. In this sense, this study can greatly benefit update of human knowledge of streamflow changes and related influencing factors in recent years. Therefore, minimum temperature, precipitation, relative humidity, solar radiation and wind speed, and also human activities, i.e., Gross Domestic Product (GDP), population intensity and land use and cover changes (LUCC), to streamflow changes across ten large river basins of China.

Instead of using deterministic rainfall-runoff models, the Budyko-based hydrothermal balance model was used in this current study to quantify the fractional contributions of various climatic variables and human activities to streamflow changes within ten large river basins across China based on hydrological data from 372 stations. Moreover, hydrological changes and related influencing factors in recent 2001-2014 were also analyzed and this point clearly differentiate this study from previous studies. The Budyko framework (Budyko, 1974), which expresses the 
interaction amongst climate, hydrology, and catchment characteristics, has been widely applied to evaluate quantitatively impacts of climatic variables and human activities on streamflow changes (e.g. Yang and Yang 2011; Tang et al., 2013; Xu et al., 2014; Tan and Gan, 2015; Liang et al., 2016; Wang et al., 2016). The trends of the streamflow and climatic variables were also quantified using the modified Mann-Kendall (MMK) statistic, and the change points were also detected using statistical methods.

The scientific issues this study attempts to address are: (1) What are the potential driving factors behind streamflow variations in 10 river basins across China? (2) What are the exact fractional contributions of each individual influencing factor to streamflow changes? (3) What could be the uncertainty in the evaluation results? This study involves the potential driving factors that may not be well considered in the hydrological literature, and has the potential to better simulate streamflow variation (Yang and Yang, 2011). Moreover, this study quantifies the fractional contributions of various driving factors to streamflow changes in 10 river basins emphasizing different behaviors of driving factors considered in modifying streamflow changes for a specific river basin. Hence, this study can help provide a basis for management of water resources and agricultural irrigation in China under impacts of changing environment in terms of climate change and human activities.

\section{Data}

Hydrological data analyzed in this study are monthly streamflow data from 372 

be found in Fig. 1. Besides, annual streamflow data covering the 2001-2014 period were also collected from 41 stations. The hydrological data were collected from the Ministry of Water Resources, China, and the quality of the hydrological data was firmly controlled before its release. The missing data accounted for less than $1 \%$ of the total data and were processed using the 7-year moving average method. Daily meteorological data, such as precipitation, maximum and minimum temperature, wind speed and relative humidity, were collected from 815 stations covering the 1960-2014 period. The meteorological data were obtained from the Climatic Data

Center, National Meteorological Information Center, China Meteorological Administration, and the quality of the hydrological data was firmly controlled before its release. The missing meteorological data were processed based on the method by Zhang et al. (2011). The 10 large river basins considered in this study were: The Pearl River basin (PR), the Yangtze River basin (YZR), the Huai River basin (HuR), the Hai River basin (HR), the Yellow River basin (YR), the Liao River basin (LR), the Songhua River basin (SHR), the Southeast River basins (SER), the Southwest 197 River basins (SWR) and the Northwest River basins (NWR) (Fig. 1). The basic 198 information of ten large river basins has been displayed in Table 1. The elevation dataset was the 30 -arc-second (1-km) gridded, quality-controlled 200 global Digital Elevation Model (DEM) obtained from http://www.ngdc.noaa.gov 201 /mgg/topo/globe.html. The drainage basin area was extracted from this elevation dataset (Fig. 1). Spatial interpolation of meteorological data was based on the inverse 
203

distance weighted method, considering the impact of altitude on the spatial distribution of meteorological factors, and the spatial resolution was $100 \times 100 \mathrm{~m}$. The areal average data of meteorological variables of each sub-catchment was obtained, based on the Zonal Histogram tool of ArcGIS software package. Furthermore, information on 475 water reservoirs was collected, such as building time, water storage capacity and locations (Fig. 2). The GDP, population density data with spatial resolution of $1 \mathrm{~km} \times 1 \mathrm{~km}$ and land use/land cover data during 2000 were also collected from the Data Center of Resources and Environment, Chinese Academy of Sciences (Fig. 2). And the quality of this dataset was also firmly controlled by Chinese Academy of Sciences, China.

\section{Methodology}

3.1 Elasticity of each potential driving factors to streamflow changes

Quantitative identification of factors driving streamflow variations has attracted considerable concern. In general, two types of methods have been used in related studies, i.e. hydrological modelling techniques and Budyko hypothesis (Budyko, 1974; Wang, 2014). Hydrological models can well describe changes of hydrological variables. However, the uncertainty related to model structure and parameters and also independence of model parameters violates the interactions between climatic and geographical variables within a river basin, which limit the performance of hydrological models (e.g. Sivapalan, 2003). At shorter time scales, such as daily or monthly time scales, hydrological modelling is in an unshakable position for the 
analysis of hydrological processes; at longer time scales, however, the Budyko framework is a recommended alternative method (Dooge et al., 1992; Zheng et al., 2009; Xu et al., 2014).

Budyko (1974) summarized that the primary factors controlling evapotranspiration rate for a long-term mean were the available energy and water and the annual water balance can be expressed in a function of available water and energy. The potential evapotranspiration $\left(\mathrm{E}_{0}\right)$ can be used to measure the available energy, while precipitation $(\mathrm{P})$ can be used to measure the availability of water.

233 Therefore, the Budyko hypothesis can be expressed as:

$234 \quad \frac{E}{P}=F\left(E_{0} / P\right)$

235 in which the function $F$ was supposed to have a common form.

236 Yang and Yang (2011) deduced the fluvial hydro-thermal balance equation based 237 on Budyko hypothesis as:

$238 \quad E=\frac{P E_{0}}{\left(P^{n}+E_{0}^{n}\right)^{1 / n}}$

239 where $E$ denotes the long-term annual average actual evaporation, $P$ is the long-term 240 annual average precipitation, $E_{0}$ is the long-term annual average potential 241 evaporation, and $n$ is the underlying surface parameter. For the long-term catchment 242 water balance (e.g., more than 10 years), soil water storage can be neglected. Based 243 on the water balance equation, $R=P-E$, we can have $R=f\left(P, E_{0}, n\right)$. Streamflow 244 changes can be computed by the following differential equation:

$\begin{array}{rl}245 & d R=\frac{\partial f}{\partial P} d P+\frac{\partial f}{\partial E_{0}} d E_{0}+\frac{\partial f}{\partial n} d n \\ 246 \quad \frac{d R}{R} & =\left(\frac{\partial f}{\partial P} \frac{P}{R}\right) \frac{d P}{P}+\left(\frac{\partial f}{\partial E_{0}} \frac{E_{0}}{R}\right) \frac{d P}{E_{0}}+\left(\frac{\partial f}{\partial n} \frac{n}{R}\right) \frac{d n}{n}\end{array}$ 
$247 \quad \frac{d R}{R}=\varepsilon_{P} \frac{d P}{P}+\varepsilon_{E_{0}} \frac{d E_{0}}{E_{0}}+\varepsilon_{n} \frac{d n}{n}$

248 where $\varepsilon_{P}=\frac{\partial f}{\partial P} \frac{P}{R}, \varepsilon_{E_{0}}=\frac{\partial f}{\partial E_{0}} \frac{E_{0}}{R}, \varepsilon_{n}=\frac{\partial f}{\partial n} \frac{n}{R}, \varepsilon_{P}, \varepsilon_{E_{0}}, \varepsilon_{n}$ denotes the elasticity of

249 precipitation, potential evaporation and parameter $n$ of LUCC to streamflow.

250 The Penman-Monteith equation by FAO is (Allen and Ingram, 1998):

251

$E_{0}=\frac{0.408 \Delta\left(R_{n}-G\right)+\gamma \frac{900}{T_{\text {mean }}+273} U_{2}\left(v p_{s}-v p\right)}{\Delta+\gamma\left(1+0.34 U_{2}\right)}$

where $E_{0}$ is the reference evapotranspiration $\left(\mathrm{mm} \mathrm{day}^{-1}\right), R n$ the net radiation at

253 the crop surface $\left(\mathrm{MJ} \mathrm{m}^{-2}\right.$ day $\left.^{-1}\right), G$ is the soil heat flux density ( $\mathrm{MJ} \mathrm{m}^{-2}$ day $\left.^{-1}\right), T$ is the

254 mean daily air temperature at $2 \mathrm{~m}$ height $\left({ }^{\circ} \mathrm{C}\right), U_{2}$ the wind speed at $2 \mathrm{~m}$ height (m

$\left.255 \mathrm{~s}^{-1}\right), v p_{s}$ the saturation vapor pressure $(\mathrm{kPa}), v p$ the actual vapor pressure $(\mathrm{kPa})$,

$256 v p_{s^{-}} v p$ the saturation vapor pressure deficit $(\mathrm{kPa}), \Delta$ the slope of the vapor pressure

$257\left(\mathrm{kPa}^{\circ} \mathrm{C}^{-1}\right)$, and $\gamma$ the psychrometric constant $\left(\mathrm{kPa}^{\circ} \mathrm{C}^{-1}\right)$. The unit conversion between

258 MJ and Watt is: 1000 Watts $\bullet h=3.6$ MJ. It should be noted here that in the

259 above-mentioned equation, the maximum and minimum temperatures are

260 independent and their fractional contribution to streamflow changes should be

261 computed independently.

262

The net radiation, $R_{n}$, is the difference between incoming net shortwave

263 radiation $\left(R_{n s}\right)$ and the outgoing net long-wave radiation $\left(R_{n l}\right)$ :

$R_{n}=(1-\alpha)\left(a_{s}+b_{s} \frac{n}{N}\right) R_{a}-\delta\left(\frac{T_{\max }{ }^{4}+T_{\min }{ }^{4}}{2}\right)\left(0.56-0.08 \sqrt{e_{a}}\right)\left(0.1+0.9 \frac{n}{N}\right)$

265

where $n$ is the actual duration of sunshine (hour), $N$ is the maximum possible duration of daylight hours (hour), $a_{s}$ is the regression constant, $a_{s}+b_{s}$ is the fraction

268 of extraterrestrial radiation reaching the earth on clear days $(n=N), R_{a}$ is the 


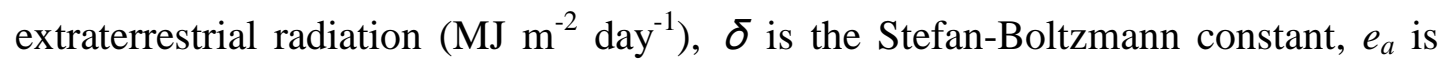
the actual vapor pressure that can be calculated from the relative humidity, and the 271 computation procedure can be found in Chapter 3 of the FAO paper 56 (Allen et al., 272 1998). based on pan evaporation equation to quantify the fractional contribution of 275 meteorological factors to pan evaporation changes, i.e.:

277 Yang and Yang (2011) deduced the general differential equation quantifying the 278 fractional contribution of solar radiation, temperature, relative humidity and wind 279 speed to potential evapotranspiration, i.e.:

$$
d E_{0} \approx \frac{\partial E_{0}}{\partial R n} d R n+\frac{\partial E_{0}}{\partial T} d T+\frac{\partial E_{0}}{\partial U_{2}} d U_{2}+\frac{\partial E_{0}}{\partial R H} d R H
$$
obtained as:

$$
\begin{gathered}
283 d E_{0} \approx \frac{\partial E_{p}}{\partial R n} d R n+\frac{\partial E_{0}}{\partial T} d T_{\text {max }}+\frac{\partial E_{0}}{\partial T} d T_{\text {min }}+\frac{\partial E_{0}}{\partial U_{2}} d U_{2}+\frac{\partial E_{0}}{\partial R H} d R H \\
\frac{d E_{0}}{E_{0}} \approx\left(\frac{R n}{E_{0}} \frac{\partial E_{0}}{\partial R n}\right) \frac{d R n}{R n}+\left(\frac{T_{\text {max }}}{E_{0}} \frac{\partial E_{0}}{\partial T_{\text {max }}}\right) d T_{\text {max }}+\left(\frac{T_{\text {min }}}{E_{0}} \frac{\partial E_{0}}{\partial T_{\text {min }}}\right) d T_{\text {min }} \\
284+\left(\frac{U_{2}}{E_{0}} \frac{\partial E_{0}}{\partial U_{2}}\right) \frac{d U_{2}}{U_{2}}+\left(\frac{R H}{E_{0}} \frac{\partial E_{0}}{\partial R H}\right) \frac{d R H}{R H}
\end{gathered}
$$

285 With the combination of Equation (5), the following equation can be obtained as:

$$
\frac{d R}{R}=\varepsilon_{P} \frac{d P}{P}+\varepsilon_{n} \frac{d n}{n}+\varepsilon_{R n} \frac{d R n}{R n}+\varepsilon_{T_{\max }} \frac{d T_{\max }}{T_{\max }}+\varepsilon_{T_{\min }} \frac{d T_{\min }}{T_{\min }}+\varepsilon_{U_{2}} \frac{d U_{2}}{U_{2}}+\varepsilon_{R H} \frac{d R H}{R H}
$$

287 Where $\varepsilon_{R_{n}}=\varepsilon_{E_{0}} \frac{R_{n}}{E_{0}} \frac{\partial E_{0}}{\partial R_{n}}, \quad \varepsilon_{T_{\max }}=\varepsilon_{E_{0}} \frac{T_{\max }}{E_{0}} \frac{\partial E_{0}}{\partial T_{\max }}, \quad \varepsilon_{T_{\min }}=\varepsilon_{E_{0}} \frac{T_{\min }}{E_{0}} \frac{\partial E_{0}}{\partial T_{\min }}, \quad \varepsilon_{U_{2}}=$ $288 \varepsilon_{E_{0}} \frac{U_{2}}{E_{0}} \frac{\partial E_{0}}{\partial U_{2}}, \varepsilon_{R H}=\varepsilon_{E_{0}} \frac{R H}{E_{0}} \frac{\partial E_{0}}{\partial R H} \varepsilon_{R_{n}}, \varepsilon_{T_{\max }}, \varepsilon_{T_{\min }}, \varepsilon_{U_{2}}$ and $\varepsilon_{R H}$ denote the elasticity 289 of solar radiation, maximum temperature, minimum temperature, wind speed and 
relative humidity to streamflow changes.

3.2 Fractional contribution of influencing factors to streamflow variations

Based on Equation (10), the fractional contribution of each individual equation:

where $R$ is the long-term annual average streamflow, $\mathrm{x}$ denotes the long-term annual average of each influencing factor, such as precipitation, LUCC, solar radiation, maximum air temperature, minimum air temperature, wind speed and relative humidity. $\Delta R_{x}$ denote the streamflow changes due to each influencing factor.

$301 \Delta \mathrm{x}$ denotes the change of long-term annual average of each factor. Tan et al. (2015) made an attribution analysis of streamflow changes in Canada using Equation (5), showing that the underlying parameter, $n$, can be used in mirroring the impacts of human activities on streamflow changes, such as building of water reservoirs, land use and land cover changes. Climate change tends to exert impacts on streamflow changes

306 via variations of precipitation, temperature, relative humidity and so on. The total 307 streamflow changes as a result of influences of the above-mentioned meteorological 308 variables can be evaluated as:

$\delta R_{\text {clim }}=\frac{\Delta R_{\text {clim }}}{\Delta} \times 100 \%, \delta R_{\text {hum }}=\frac{\Delta R_{\text {hum }}}{\Delta} \times 100 \%$

where $\delta R_{\text {clim }}$ and $\delta R_{\text {hum }}$ are the fractional contributions of climate change and

311 human activities to streamflow changes with unit of $\% . \Delta$ denotes the total amount of 312 human- and climate-induced streamflow changes. 
Detection of trends was done, based on the modified Mann-Kendall statistic

316 (MMK) as recommended by Hamed and Rao (1998). This method was with 317 amended variance when the lag- $i$ autocorrelation coefficients were significantly 318 different from zero at the 95\% confidence level. Hamed and Rao (1998) have shown 319 MMK with consideration of lag- $i$ autocorrelation and related robustness to 320 autocorrelation. In this study, the significance level for MMK was set at 0.05.

321 Detection of change points was done, based on a variety of appropriate methods, 322 including a kind of fully-integrated "changepoint" method Killick and Eckley (2014) 323 developed the $\mathrm{R}$ package, changepoint, which is free of the normality assumption 324 and can be used in detection of multiple change points. Villarini et al. (2009) 325 suggested Pettitt test to analyze the change point. Compared the performances of 8 326 change-point test methods, Liu et al. (2015) found that the Ordered Clustering test 327 was more effective in detection of detect change points. Hence, in this study, AMOC, 328 Ordered Clustering Test method, and Pettitt test method were used for the detection 329 of change points. To avoid possible uncertainty and misleading results based on the 330 individual method, the assembled change points were obtained, based on more than 331 one method. If the results are all different, the median change point would be 332 selected.

\section{Results}

4.1 Timing of change points of streamflow series 
streamflow changes were evaluated, based on coincident change points with the aim to compare the impacts of human activities and climate change on instream flow 338 changes in different river basins considered in this study. The length of streamflow 339 time series was mostly 41 years, i.e. during 1960-2000, being comparatively short. 340 Besides, the building time of water reservoirs in different river basins and even in 341 one river basin was different. It was therefore almost impossible and infeasible to 342 subdivide streamflow series with different building times of numerous water 343 reservoirs. Poff et al. (2007) suggested the mean building time of one river basin as 344 the time point for subdivision of streamflow series. Tan and Gan (2015) argued that 345 the mean time of the change points can be taken as time point for subdivision of 346 streamflow series of the study region. Fig. 3a illustrates the building times of 475 347 water reservoirs considered in this study, showing that the $50 \%$ and $75 \%$ percentile 348 values of the building times of almost all river basins, except SWR, was 1980 or just 349 before 1980 respectively. The mean building time of all water reservoirs across 350 China is 1972 . Furthermore, Fig. $3 \mathrm{~b}$ illustrates the detection results of change points 351 of streamflow series from 372 stations across China, showing distinct differences in 352 change points of streamflow series. However, it can be seen from Fig. $3 b$ that the $50 \%$ 353 percentile value of streamflow changes is mostly before 1980, and the mean time of 354 the change points of streamflow series is around 1980. It should be noted here that 3551980 is the time when Reform and Open policy in China started, and the building of 356 hydraulic engineering facilities and water reservoirs being pursued vigorously to 357 satisfy the development of agriculture and industry and this point well justify the 
358

time point of abrupt changes of streamflow series. In this case, the time point of 1980 was accepted as the change point for streamflow series across China and the entire streamflow series were subdivided into to two time intervals, i.e. period 1 (1960-1979) and period 2 (1980-2000).

\subsection{Changing properties of hydrometeorological variables}

Fig. 4 demonstrates the MMK trends of annual precipitation, maximum/minimum air temperature, relative humidity, solar radiation, and wind speed during 1960-2000 and streamflow changes during period 2 relative to those during period 1. The MMK statistic value of greater (smaller) than $1.96(-1.96)$ shows significant increasing (decreasing) trend at 95\% confidence level. Trends of annual precipitation were subject to distinct spatial distribution pattern. Significant decreasing annual precipitation can be observed in the YR, HR, LR, central parts of YZR and also central and western parts of the PR. The decreasing magnitude of areal average annual precipitation during period 2 reached $10 \%$ when compared to that during period 1 . Other regions were dominated by increasing annual precipitation, specifically annual precipitation in the SHR and Poyang basin during the period 2 was $10 \%$ more than that during period 1 . The areal average annual precipitation variability ranged between $-22 \%-20 \%$ (Fig. 4a). The maximum air temperature changes were subject to different patterns in northern and southern China (Fig. 4b): increasing maximum air temperature was found in northern China and decreasing (even significant decreasing) maximum air temperature in southern China. However, 
different spatial patterns were identified for minimum air temperature when compared to those of maximum air temperature (Figs. 4c, 4b). Generally increasing minimum air temperature was observed except for parts of central China. Increasing and significant increasing minimum air temperature were detected mainly in 384 northern China. The relative humidity (Fig. 4d) was generally increasing, 385 particularly in southern China. Specifically, a more evident increase of relative 386 humidity was observed in most parts of the YZR, SWR. The relative humidity 387 tended to decrease in northeastern China. Increasing minimum temperature and 388 increasing annual precipitation should be one of the causes for increasing relative humidity in southern China. Solar radiation changes (Fig. 4e) were in adverse spatial patterns when compared to maximum air temperature: decreasing solar radiation in northeastern and northern China but increasing solar radiation in southern China, which should be attributed to increased aerosol in northern China. Decreasing wind speed was dominant across China except some specific parts of river basins which 394 should be due to the underlying surface properties, such as land use and land cover 395 changes such as urbanization (Li et al., 2008).

When it comes to underlying parameters, $n$ (Fig. $4 \mathrm{~g}$ ), decreased $n$ was identified 397 in the western parts of SHR, middle and lower YZR and parts of the PR. Other 398 regions were dominated by increased $n$ values, and it was particularly true for the $n$ 399 values in the YR and HR, being about $0.21-0.98$ as the increasing magnitude, 400 implying intensifying human activities in these regions and these intensifying human 401 activities had the potential to decrease streamflow amount. 

streamflow, streamflow coefficient and annual streamflow during 1960-2000 and 404 annual streamflow changes during period 2 relative to those during period 1. 405 Increasing monthly minimum streamflow can be observed mainly in the PR, YZR, 406 SER, SWR and NWR, and particularly significant increasing trends were detected 407 mainly in the SER, YZR and SWR. The monthly maximum streamflow (Fig.5b) 408 have partly different spatial patterns when compared to monthly minimum 409 streamflow (Fig. 5a). Significant increasing trends were detected mainly in few 410 watersheds in YZR. Specifically, significant decreasing trends with larger decreasing 411 magnitude were observed in the YR and HR. The MMK trends of streamflow 412 coefficient (Fig. 5c) were in adverse spatial patterns when compared to the relative 413 changes of $n$ (Fig. $4 \mathrm{~g}$ ): the positive $n$ values resulted in the decreasing trends of 414 streamflow coefficient and were observed mainly in northern China, and negative $n$ 415 values resulted in the increasing trends of streamflow coefficient and were observed 416 mainly in southern China. As shown in Fig. 6, the MMK trends of streamflow 417 coefficient were in linear relations with those of underlying surface parameters, i.e., $418 n$, with $R^{2}$ of 0.491 and $P<0.0001$. The changes of underlying surface can be one of 419 the most important influencing factor behind runoff coefficient changes.

420 The annual streamflow depth (Fig. 5d) was subject to similar spatial patterns 421 when compared to those of annual precipitation (Fig. 4a), which clearly indicated 422 that precipitation changes still occupied the unshakable position for streamflow 423 changes. Increasing trends of annual streamflow depth were found mainly in the 
424

425

426

428

430

432

433

434

436

437

438

441 (Zhang et al., 2015).

lower SHR, LR, HR and YR, and particularly significant decreasing trends of annual streamflow depth were detected mainly in the YR and HR. The decrease of annual streamflow depth reached as much as $31 \mathrm{~mm}$. Increased annual streamflow depth was observed mainly in the YZR, PR, SER, SWR and NWR, and particularly significant increasing annual streamflow depth was detected in the middle and lower YZR basin and also in the NWR. In general, decreasing annual streamflow depth was detected mainly in northern China and increasing annual streamflow depth in southern China. However, it should be clarified here that spatial patterns of annual precipitation and annual streamflow depth matched considerably well, but not perfectly good. For example, the lower SHR basin was mainly characterized by increasing annual precipitation but decreasing annual streamflow depth. Similarly, the headwater regions of the YR were mainly dominated by increased annual precipitation but decreased annual streamflow depth. However, the underlying parameter, $n$, has an increasing tendency, showing the enhancing influence of human activities on streamflow changes in these two regions. Therefore, it can be said that streamflow changes were impacted by both climate change and human activities and the influencing degrees were different from one river basin to another across China 
reflect the sensitivity of streamflow changes to influencing factors (Xu et al., 2014).

447 It can be seen from Fig. 7 that the sensitivity of streamflow changes to various

448 influencing factors was distinctly different from one river basin to another. Generally,

449 the elasticity of streamflow changes to influencing factors was larger in river basins

450 in northern China than that of those in southern China. The elasticity coefficients of

451 streamflow changes to precipitation ranged between 1.62-4.84 with a mean value of

4522.24 in the SHR, LR, HR, YR and HuR, indicating that an increase of $10 \%$ in

453 precipitation caused an increase of $22.4 \%$ in streamflow. However, the elasticity

454 coefficients of streamflow changes to precipitation ranged between 1.05-1.61 with a

455 mean value of 1.57 in the YZR, PR, SWR and SER, showing that an increase of $10 \%$

456 in precipitation would cause a $15.7 \%$ increase of streamflow. LUCC had negative

457 effects on streamflow changes with elasticity coefficients between -1.46--5.07 in

458 most basins of northern China, and with a mean elasticity coefficient of -10.85

459 across china, implying that a $10 \%$ increase of LUCC parameter, $n$, would cause a

$460 \quad 14.6 \%-50.7 \%$ decrease of streamflow.

461 Generally, increasing precipitation and relative humidity increased streamflow

462 but increasing maximum/minimum temperature, solar radiation, wind speed and

463 LUCC tended to decrease streamflow because maximum/minimum temperature,

464 solar radiation, wind speed tended to increase evapotranspiration. It can be found

465 from Fig. 7 that streamflow changes were more sensitive to precipitation changes

466 and LUCC than other influencing factors considered in this study. Specifically,

467 streamflow variations in the LR were highly sensitive to precipitation changes and 
468 469 470 471

streamflow variations in the NWR were highly sensitive to LUCC. Generally, streamflow processes in river basins of northern China were more sensitive to various influencing factors than southern China, being reflected by larger elasticity coefficients of streamflow variations to climate changes and LUCC in river basins of northern China than in river basins of southern China. Specifically, based on elasticity coefficients the streamflow changes to influencing factors, the order of the influencing factors was, respectively: precipitation $>$ LUCC $>$ relative humidity $>$ solar radiation $>$ maximum air temperature $>$ wind speed $>$ minimum air temperature. These results were in good agreement with those by Yang and Yang (2011) in YR and HR.

\subsection{Impacts of influencing factors on streamflow changes}

Fig. 8 compares simulated streamflow, i.e. $\Delta R_{P}+\Delta R_{n}+\Delta R_{R n}+\Delta R_{\text {Tmax }}+$ $\Delta R_{T \min }+\Delta R_{U 2}+\Delta R_{R H}$, and observed streamflow. It can be seen that simulated and observed streamflow matched statistically well with a correlation coefficient of 0.996 and the mean absolute error (MEA) between simulated and observed streamflow depths was $2.41 \mathrm{~mm}$. The relative error was $4.89 \%$. Hence, the

Budyko-based hydrothermal coupled balance model was used in this study to differentiate influencing factors for streamflow changes across China. Fig. 9 shows different influences of various influencing factors on streamflow changes in space. It can be seen that precipitation increased the streamflow amount in the most hydrological stations among the SHR, middle and lower YZR, lower PR, SER, SWR 
and NWR. Particularly, precipitation changes caused $81 \mathrm{~mm}$ in streamflow depth in 491 the lower YZR, which should be due to a significant increase of precipitation amount 492 and also precipitation intensity in the lower YZR (e.g. Zhang et al., 2008). The river 493 basins with a decrease in annual precipitation (Fig. 9a) were mostly characterized by 494 decreased streamflow, such as south parts of the LR, HR, YR, HuR and middle and 495 lower PR. Specifically, a decrease by $40 \mathrm{~mm}$ in streamflow depth was found in the 496 YR, HR, middle YZR and also in the middle PR (Fig. 9a). Impacts of temperature changes on streamflow were relatively spatially complicated. The maximum air 498 temperature generally increased streamflow in river basins of southern China (Fig. 9b) but decreased streamflow of river basins in northern China. However, the 500 minimum air temperature increased slightly streamflow in the central China, but 501 decreased streamflow in other river basins (Fig. 9c). Spatial patterns of impacts of 502 relative humidity on streamflow were relatively complex (Fig. 9d). The relative 503 humidity tended to increase streamflow in the middle and lower YZR, contributing 504 to $2.0-7.1 \mathrm{~mm}$ increase in streamflow depth. The impacts by solar radiation and wind 505 speed were relatively minor (Figs. 9e and 9f). However, LUCC had a considerable 506 effect on streamflow changes with evident spatial variability. LUCC tended to 507 decrease streamflow at most river basins considered in this study, and it was 508 particularly the case for streamflow amount in the lower SHR, HR, YR, HuR, 509 northwest parts of YZR, NWR and SWR.

510 Fig. 10 shows influences of various influencing factors on streamflow changes 511 during 2001-2014 relative to streamflow changes during the period of 1960-1979. 
512 Visual comparison between Figs. 9 and 10 indicate similar spatial patterns of 513 streamflow changes due to influencing factors considered in this study. However, the 514 difference lies in the higher sensitivity of streamflow changes to human activities, i.e. 515 underlying parameters. In other words, human activities exerted intensifying impacts 516 on streamflow changes. Besides, air temperature, relative humidity and wind speed 517 also tended to have enhancing impacts on streamflow changes. Comparatively, 518 impacts of precipitation changes on streamflow changes were decreasing. 519 Particularly significant impacts of intensifying human activities on streamflow 520 processes should arouse considerable concerns in modelling of hydrological 521 processes and in the management of agricultural irrigation and water resources with 522 consideration of human interferences.

523 Fig. 11 illustrates the impacts of various influencing factors on streamflow 524 changes during 1980-2000 relative to the period of 1960-1979 for each river basin. 525 Precipitation had an evident influence on streamflow changes. Precipitation change 526 tended to increase streamflow in the YZR, SER, SWR, SHR and NWR, especially in 527 the SER and SHR, Precipitation change increased streamflow in all of the 528 watersheds. Table 2 indicates that precipitation changes had the most evident impacts 529 on streamflow changes in the SER and YZR, causing $67.1 \mathrm{~mm}$ and $34.5 \mathrm{~mm}$ of 530 streamflow depth in these two river basins. However, decreased precipitation caused $53122.7 \mathrm{~mm}, 19.4 \mathrm{~mm}$ and $9.7 \mathrm{~mm}$ of streamflow depth in the HuR, HR and YR.

532 As for impacts of other influencing factors except for the above-mentioned ones, 533 wind speed generally contributed to the increase of streamflow amount and 
minimum temperature tended to decrease streamflow of the river basins considered in this study. However, the maximum air temperature and relative humidity tended to decrease streamflow in river basins of northern China and increase streamflow in river basins of southern China. Solar radiation had a limited impact on streamflow changes. LUCC generally decreased streamflow and it was particularly true for the HuR, HR and SWR with $62.1 \mathrm{~mm}, 32.8 \mathrm{~mm}$ and $23.3 \mathrm{~mm}$ of decrease of streamflow depth (Table 2). These river basins were dominated by intensifying human activities, such as increasing agricultural irrigation and increasing withdrawal of water resources due to booming socioeconomic development. However, a slight increase of streamflow was found in the PR, YR and SER with an increase in streamflow of 0.7 $\mathrm{mm}, 10.5 \mathrm{~mm}$ and $13.7 \mathrm{~mm}$. It should be attributed to decreased crop land areas in these river basins which is particularly true for the lower PR.

4.4 Climate- and human-induced impacts on streamflow changes

To further differentiate the dominant influencing factors for streamflow variations, Fig. 12 compares climate-induced streamflow changes, i.e. $\Delta R_{P}+\Delta R_{R n}+$ $\Delta R_{T \max }+\Delta R_{\text {Tmin }}+\Delta R_{U 2}+\Delta R_{R H}$, with human-induced streamflow changes, i.e. $\Delta R_{n}$. It can be seen that climate change plays a key role in modifying streamflow processes at hydrological stations in southern China and northwestern China. For streamflow changes in river basins in northern China, human activities have more impacts on streamflow variations than does climate change, such as the lower SHR, HR, middle LR and most parts of YR. Table 3 shows that climate change tends to increase the 
streamflow amount in river basins of southern China, such as PR, YZR, SHR, SER, and SWR; and decreases streamflow in river basins of southern China, such as HR,

558 HuR, YR, and LR during 1980-2000 period. Generally, human activities play a 559 dominant role in the reduction of streamflow and it is particularly true for 560 streamflow changes in YR. Human activities cause a $19.4 \mathrm{~mm}$ decrease in 561 streamflow depth, which should be attributed to massive ecological conservation in 562 the YR (Liang et al., 2015). In general, the fractional contribution from climate 563 changes and human activities to streamflow changes is, respectively, $71.0 \%$ and $29.0 \%$ 564 across China.

Fig. 12b shows potentially dominant influencing factors for streamflow changes 566 during 2001-2014 as compared to those during 1960-1979. The hydrological data 567 collected at 41 stations can well represent hydrological processes of major river 568 basins considered in this study. It can be seen that climate change still played a key 569 role in modifying hydrological processes, and streamflow changes at 27 out of 41 570 stations were mainly due to climate changes during1960-2000 period. During 571 2001-2014, however, streamflow changes at 26 out of 41 stations were attributed to 572 human activities (Table 3). The dominant influencing factors for streamflow changed 573 at 22 out of 41 stations shifted from climate change to human activities, implying 574 human activities gradually played the main role in streamflow changes in recent 575 years, and this result should arouse considerable concern in terms of water resources 576 management and river basin management. In recent years, precipitation changes 577 tended to reduce streamflow, e.g. climate change caused $62.3 \mathrm{~mm}$ and $11.6 \mathrm{~mm}$ in 
streamflow depth in the PR and YZR. For streamflow changes across China in recent years, the fractional contribution of climate change and human activities to streamflow changes was $53.5 \%$ and $46.5 \%$, respectively. Therefore, the fractional contribution of human activities to streamflow changes during 2001-2014 period was significantly greater than that during 1980-2000 period, implying that the human activities tended to enhance the impacts on streamflow changes.

\section{Discussions}

5.1 Human-induced impacts on streamflow change

The availability of data concerning human activities is usually not ideal and it is often done, based on certain human activity index during a certain year or certain time interval. Long-term dataset is often not available (e.g. Wang and Hejazi 2014; Tan and Gan, 2015). Particularly, water reservoirs, cropland, population density and GDP are subject to huge spatial diversity and/or spatial heterogeneity within ten river basins across China (Fig. 2). Therefore, it is necessary to differentiate influences of these diverse human activities on streamflow changes at finer spatial scales. In this study, 372 tributaries controlled by hydrological stations considered in this study were categorized into ten groups, based on degrees of influences of human activities on streamflow changes. Then, comparison was done between mean human contribution to streamflow changes and related human activities (Fig. 13). It can be seen from Fig. 13 that human-induced streamflow change was negatively related to cropland changes. Increasing cropland can be expected to increase agricultural 
600 irrigation, increase evapotranspiration and hence decrease streamflow. The storage of 601 water reservoirs was also negatively related to human-induced streamflow variations 602 (Fig. 13b). The storage of reservoirs was directly related to the impoundment effects. 603 Besides, reservoirs with larger storage capacity increase water evaporation. These 604 factors all decrease the streamflow amount of a river basin. Besides, the population 605 and GDP are also important influencing factors for streamflow. Figs. 13c and 11d 606 indicate that these two factors had significant negative relations with human-induced 607 streamflow changes, implying that the higher the population density and 608 socioeconomic development, the more the decrease of streamflow. Higher 609 population density implies more human demand of water resources and vice versa. 610 Specifically, the relationship was uncertain between human-induced streamflow 611 changes, population density and GDP density in the watersheds where human 612 activity can increase streamflow depth. Generally, higher population and GDP 613 tended to increase the human use of fresh water and hence decreased streamflow. 614 The human-induced increased streamflow could be attributed to other factors, e.g., 615 deforest, urbanization and so forth, rather than the population and GDP. For example, 616 in Poyang Lake basin, economic development and population growth caused 617 increasing human use of water resources and reduced the streamflow; however, 618 deforestation and lakes landfill significantly increased the streamflow (e.g. Zhang et 619 al., 2016). Therefore, increasing streamflow cannot be attributed to population and 620 GDP themselves. 


\subsection{Uncertainty in attribution analysis}

Tang et al. (2013) evaluated the impacts of various meteorological variables on streamflow changes at the Huayuankou station, the middle YR, indicating that relative to streamflow changes during 1960-1990, the fractional contribution of precipitation, solar radiation, air temperature, wind speed and relative humidity to streamflow changes during 1991-2002 was, respectively, $-27.3 \%, 1.7 \%,-3.5 \%, 6.7 \%$, $-1.7 \%$. In this study, the fractional contribution of solar radiation, maximum temperature, minimum temperature, wind speed and relative humidity to streamflow changes was, respectively, $-43.3 \%, 1.0 \%,-3.7 \%,-3.2 \%, 7.1 \%,-1.8 \%$. These results were largely in good line with differences due to the computation of elasticity coefficient based on different potential evapotranspiration models and comparison of different time intervals.

Furthermore comparison was also done between results of this study (Table 3) and of other published ones (Table 4), showing that the dominant influencing factors obtained by this study for each individual river basin were similar, but were still slightly different from those by other researchers. For example, based on the results of this study, the fractional contribution of climate change to streamflow changes in the YR and HuR during 1980-2000 was, respectively, $78.7 \%$ and $22.7 \%$ and this fractional contribution obtained by published researches was, respectively, $72 \%$ (Zhao et al., 2015) and 33\% (Zhang et al., 2016). These differences were attributed to choices of different methods and also the time intervals considered in each study. When compared to results by hydrological models (Table 4), the results by this study 
644 for climate-induced streamflow changes seemed to be underestimated for river 645 basins in northwestern China and southwestern China. The streamflow changes of 646 the river basins in these regions were partly from melting snow or glaciers. Impacts 647 of air temperature on streamflow changes were realized via evapotranspiration but 648 not via impacts of temperature on the melting processes of snow or glacier, this point 649 should be the cause behind the underestimation of fractional contribution of climate 650 change to streamflow changes. The Budyko-based model also had limited performance in differentiating the 652 influencing factors for streamflow changes. When meteorological variables, such as 653 precipitation, are subject to moderate variability, the fractional contribution of each 654 meteorological variable to streamflow changes is statistically acceptable with an 655 acceptable error. The larger the changing variability of meteorological variables the 656 larger the error in the fractional contribution evaluated by Budyko-based model (e.g. 657 Yang et al., 2014). Yang et al. (2014) pointed out that a $10 \mathrm{~mm}$ increase of long-term 658 annual average precipitation can cause a $0.5-5 \%$ in error in the precipitation-induced 659 contribution to streamflow changes, and when the increase of long-term annual 660 average precipitation reached $50 \mathrm{~mm}$, the error increased to $2.5-25 \%$. Besides, more 661 rainstorms or more intensifying precipitation events, the fractional contribution of 662 underlying parameter, $n$, to streamflow changes decreased (Donohue et al., 2012). 663 Though the Budyko-based model had a certain uncertainty in modelling the 664 influencing factors for streamflow changes, the Budyko-based model effectively 665 avoided negative impacts of complicated parameterization and model structure of 

differentiating influencing factors for streamflow changes for multiple river basins across a relative large territory.

\section{Conclusions}

This study evaluated quantitatively the fractional contribution of climate change,

672 i.e. precipitation, air temperature, relative humidity and so on, and human activities,

673 i.e. building of water reservoirs, cropland, GDP and population density, to streamflow 674 changes within ten river basins. The elasticity of meteorological variables to 675 streamflow changes was obtained, based on the Penman-Monteith evapotranspiration 676 model for maximum/minimum temperature, relative humidity, precipitation and solar 677 radiation. Besides, comparison was done between research results of this current study 678 and those of published researches. This investigation led to the following conclusions:

679 (1) Elasticity coefficients of climate change and human activities to streamflow 680 changes in river basins of northern China are significantly larger than those in 681 southern China, implying higher sensitivity of streamflow changes to changing 682 environments in northern China than those in southern China. Thus, more 683 importance should be attached to water resources management in northern China. 684 Generally, increasing precipitation and relative humidity tend to increase 685 streamflow and the maximum/minimum air temperature, solar radiation, wind 686 speed and LUCC have negative influences on streamflow changes. For streamflow 687 changes across China, the influencing factors with larger to smaller sensitivity of 
688 streamflow changes are: Precipitation > LUCC > relative humidity > solar 689 radiation $>$ maximum air temperature $>$ wind speed $>$ minimum air temperature.

690 (2) Climate change impacts streamflow variations via precipitation, temperature and 691 relative humidity. Meteorological variables have different influences on 692 streamflow changes. During 1980-2000, precipitation tended to increase 693 streamflow across China with a $12.1 \mathrm{~mm}$ increase in streamflow depth. Wind speed 694 generally contributed to the increase of streamflow amount and minimum 695 temperature tended to decrease streamflow of the river basins. Maximum air 696 temperature and relative humidity tend to decrease streamflow in river basins of 697 northern China and tend to increase streamflow in river basins of southern China. 698 Solar radiation has a limited impact on streamflow changes. Generally, 699 precipitation is one of the meteorological variables which has the largest effect on 700 streamflow variations. During 1980-2000, climate change increases streamflow in 701 river basins of southern China and decreases streamflow in river basins of northern 702 China, having a fractional contribution to $29.0 \%$ of streamflow changes. During 703 2001-2014, however, human activities tend to have an increasingly important role 704 in modifying streamflow variations. The fractional contribution of climate change 705 and human activities to streamflow changes is, respectively, $53.5 \%$ and $46.5 \%$. 706 Recent years have witness increasing human-induced influences on hydrological 707 processes of river basins, which pose a serious challenge in water resources 708 management.

709 (3) The Budyko based model has limited performance in differentiating influencing 

changing variability of meteorological variables. However, comparison indicates that fractional contributions of climate change and human activities differentiated by the Budyko based model and hydrological models are similar in terms of magnitude with slight differences. The differences lie in the selection of different evapotranspiration models and time intervals considered in different studies. Even so, the Budyko based model effectively avoids limitations the hydrological models have in complicated parameterization and rigorous requirements of dataset. Hence, the Budyko based model can be ideal in quantitative evaluation of the influencing factors for hydrological processes at a longer time scale.

Acknowledgments: This work is financially supported by the National Science Foundation for Distinguished Young Scholars of China (Grant No.: 51425903), the

723 Natural Foundation of Anhui Province (Grant No.: 1508085MD65), and is fully supported 724 by a grant from the Research Grants Council of the Hong Kong Special Administrative Region, 725 China (Project No. CUHK441313; HKBU 22301916). Detailed information such as data can 726 be obtained by writing to the corresponding author at zhangq68@ mail.sysu.edu.cn. Our cordial 727 thanks should be extended to Prof. Dr. Dawen Yang from Tsinghua University for his 728 professional suggestions during preparation of this manuscript. The last but not the least, our 729 cordial gratitude should be extended to the editor, Prof. Dr. Geoff Syme, and two anonymous 730 reviewers for their pertinent and professional comments and suggestions which are greatly 731 helpful for further quality improvement of this current manuscript. 
References:

734 Arnell, N.W., 1999. Climate change and global water resources. Global 735 Environmental Change 9(1), S31-S49.

736 Allen, R.G., Pereira, L.S., Raes, D., Smith, M., 1998. Crop evapotranspiration 737 guidelines for computing crop water requirements - FAO Irrigation and Drainage Paper 56. FAO, 1998. ISBN 92-5-104219-5.

Allen, M.R., Ingram, W.J., 2002. Constraints on future changes in climate and the

Bao, Z., J. Zhang, G. Wang, G. Fu, R. He, X. Yan, J. Jin, Y. Liu, A. Zhang, 2012. Attribution of decreasing streamflow of the Haihe River basin, northern China: Climate variability or human activities. Journal of Hydrology 460-461, 117-129.

Barnett, P.T., D.W. Pierce, H.G. Hidalgo, C. Bonfils, B.D. Santer, T. Das, G. Bala, A.W. Wood, T. Nozawa, A.A. Mirin, D.R. Cayan, M.D. Dettinger, 2008. Human-induced changes in the hydrology of the Western United States. Science $319,1080-1083$.

Budyko, M.I., 1974. Climate and Life, Academic, New York.

Burn, B.H., 1994. Hydrologic effects of climatic change in west-central Canada. Journal of Hydrology 160, 53-70.

Donohue, R.J., Roderick, M.L., McVicar, T.R., 2012. Roots, storms and soil pores: Incorporating key ecohydrological processes into Budyko's hydrological model. Journal of Hydrology 436, 35-50. 
Dooge, J.C., 1992. Sensitivity of streamflow to climate change: A Hortonian approach. Bulletin of the American Meteorological Society 73(12), 2013-2024.

Fan, H. and D. He, 2015. Temperature and Precipitation Variability and Its Effects on Streamflow in the Upstream Regions of the Lancang-Mekong and Nu-Salween Rivers. Journal of Hydrometeorology 16, 2248-2263.

Gardner, L.R., 2009. Assessing the effect of climate change on mean annual runoff. Journal of Hydrology 379, 351-359.

Hamed KH, Rao AR. 1998. A modified Mann-Kendall trend test for autocorrelated data. Journal of Hydrology 204(1-4), 182-196.

Hu, X., C. Wu, W. Hong, R. Qiu, J. Li, T. Hong, 2014. Forest cover change and its drivers in the upstream area of the Minjiang River, China. Ecological Indicators $46,121-128$.

Huang, J., Z. Zhang, Y. Feng, H. Hong, 2013. Hydrologic response to climate change and human activities in a subtropical coastal watershed of southeast China. Reg. Environ. Change 13, 1195-1210.

Huang, Z., Yang, H., Yang, D., 2016. Dominant climatic factors driving annual runoff changes at the catchment scale across China. Hydrology and Earth System Sciences 20(7), 2573-2587.

Killick, P., 2014. Changepoint: An R package for changepoint analysis. Journal of Statistical Software 58(3), 1-19.

Krajewski, F.W., 2009. On the stationarity of annual flood peaks in the continental United States during the 20th century. Water Resources Research 45, W08417. 
Li, L.J., L. Zhang, H. Wang, J. Wang, J.-W. Yang, D.-J. Jiang, J.-Y. Li and D.-Y. Qin, 2007. Assessing the impact of climate variability and human activities on streamflow from the Wuding River basin in China. Hydrological Processes 21,

Li, Y., Wang, Y., Chu, H.Y., Tang, J.P., 2008. The climate influence of anthropogenic land-use changes on near-surface wind energy potential in China. Chinese Science Bulletin 53(18), 2859-2866.

Liang, W., Bai, D., Wang, F., Fu, B., Yan, J., Wang, S., Yang, Y., Long, D., Feng, M., 2015. Quantifying the impacts of climate change and ecological restoration on streamflow changes based on a Budyko hydrological model in China's Loess Plateau. Water Resources Research 51(8), 6500-6519.

Liu, D., X. Chen, Y. Lian and Z. Lou, 2010. Impacts of climate change and human activities on surface runoff in the Dongjiang River basin of China. Hydrol. Process.

Liu, J.Y., Zhang, Q., Gu, X.H., 2015. Evaluation of ecological flow with considerations of hydrological alterations in the Poyang Lake basin. Acta Ecologica Sinica 35(16), 5477-5485 (in Chinese with English abstract).

Poff, N.L.R., Olden, J.D., Merritt, D.M., Pepin, D.M., 2007. Homogenization of regional river dynamics by dams and global biodiversity implications. Proceedings of the National Academy of Sciences 104(14), 5732-5737.

797 Roderick, M.L., Rotstayn, L.D., Farquhar, G.D., Hobbins, M.T., 2007. On the 

DOI: 10.1029/2007GL031166.

800 806

807

808 809

Sivapalan, M., 2003. Prediction in ungauged basins: a grand challenge for theoretical hydrology. Hydrological Processes 17, 3163-3170.

Tan, X., T.Y. Gan, 2015. Contribution of human and climate change impacts to changes in streamflow of Canada. Scientific Report 5, 17767, DOI: 10.1038/srep17767.

Tang Y, Tang Q, Tian F, Zhang, Z., Liu, G., 2013. Responses of natural runoff to recent climatic variations in the Yellow River basin, China. Hydrology and Earth System Sciences 17(11), 4471-4480.

Wang, D. and M. Hejazi, 2011. Quantifying the relative contribution of the climate and direct human impacts on mean annual streamflow in the contiguous United States. Water Resources Research 47, W00J12, doi:10.1029/2010WR010283.

Wang, S., M. Yan, Y. Yan, C. Shi, L. He, 2012. Contribution of climate and human activities to the changes in runoff increment in different sections of the Yellow River. Quaternary International 282, 66-77.

Wang, W.G., Zou, S., Shao, Q., Xing, W.Q., Chen, X., Jiao, X.Y., Luo, Y.F., Yong, B., Yu, Z.B., 2016. The analytical derivation of multiple elasticities of runoff to climate change and catchment characteristics alteration. Journal of Hydrology 541, $1042-1056$.

Wang, X., 2014. Advances in separating effects of climate variability and human activity on stream discharge: an overview. Advances in Water Resources 71, 
$\mathrm{Xu}$, J., 2011. Variation in annual runoff of the Wudinghe River as influenced by climate change and human activity. Quaternary International 244, 230-237. hypothesis for detecting the dominant cause of runoff decline in Haihe basin. Journal of Hydrology 510, 530-540.

Yang, H., J. Qi, X. Xu, D. Yang, H. Lv, 2014. The regional variation in climate elasticity and climate contribution to runoff across China. Journal of Hydrology $517,607-616$.

Yang, H., Yang, D., 2011. Derivation of climate elasticity of runoff to assess the effects of climate change on annual runoff. Water Resources Research 47(7), W07526, doi:10.1029/2010WR009287.

Zhang, M., X. Wei, P. Sun, S. Liu, 2012. The effect of forest harvesting and climatic 833 variability on runoff in a large watershed: The case study in the Upper Minjiang 835 River of Yangtze River basin. Journal of Hydrology 464-465, 1-11.

Zhang, Q., C.-Y. Xu, T. Yang. 2009. Variability of water resource in the Yellow River 837 Zhang, Z., X. Chen, C.-Y. Xu, L. Yuan, B. Yong, S. Yan, 2011. Evaluating the 838 non-stationary relationship between precipitation and streamflow in nine major 839 basins of China during the past 50 years. Journal of Hydrology 409, 81-93.

840 Zhang, Q., C.-Y. Xu, Z. Zhang, Y.D. Chen, C.-L. Liu, 2008. Spatial and temporal 841 variability of precipitation maxima during 1960-2005 in the Yangtze River basin 

353(3), 215-227.

844 Zhang, Q., V.P. Singh, J. Li, X. Chen, 2011. Analysis of the periods of maximum 845 consecutive wet days in China. Journal of Geophysical Research 116, D23106, 846 doi: 10.1029/2011JD016088.

847 Zhang, Q., X. Gu, V.P. Singh, C.-Y. Xu, D. Kong, M. Xiao, X. Chen, 2015. 848 Homogenization of precipitation and flow regimes across China: changing 849 properties, causes and implications. Journal of Hydrology 530, 462-475.

850 Zhang, Q., J. Liu, V.P. Singh, X. Gu and X. Chen, 2016. Evaluation of impacts of 851 climate change and human activities on streamflow in the Poyang Lake basin, 852 China. Hydrological Processes DOI: 10.1002/hyp.10814.

853 Zhang, S., Yang, D., Jayawardena, A.W., Xu, X. and Yang, H., 2016. Hydrological 854 change driven by human activities and climate variation and its spatial variability 855 in Huaihe Basin, China. Hydrological Sciences Journal 61(8), 1370-1382.

856 Zhao, Q., S. Liu, L. Deng, S. Dong, J. Yang, C. Wang, 2012. The effects of dam 857 construction and precipitation variability on hydrologic alteration in the Lancang 858 River Basin of southwest China. Stoch. Environ. Res. Risk Assess. 26, 993-1011. 859 Zhao, Y., Zou, X., Gao, J., Xu, X. and Wang, C., 2015. Quantifying the 860 anthropogenic and climatic contributions to changes in water discharge and 861 sediment load into the sea: A case study of the Yangtze River, China. Science of 862 The Total Environment 536, 803-812.

863 Zheng, H., Zhang, L., Zhu, R., Liu, C., Sato, Y., Fukushima, Y., 2009. Responses of 
864 streamflow to climate and land surface change in the headwaters of the Yellow 865 River Basin. Water Resources Research 45(7), DOI: 10.1029/2007WR006665. 866 


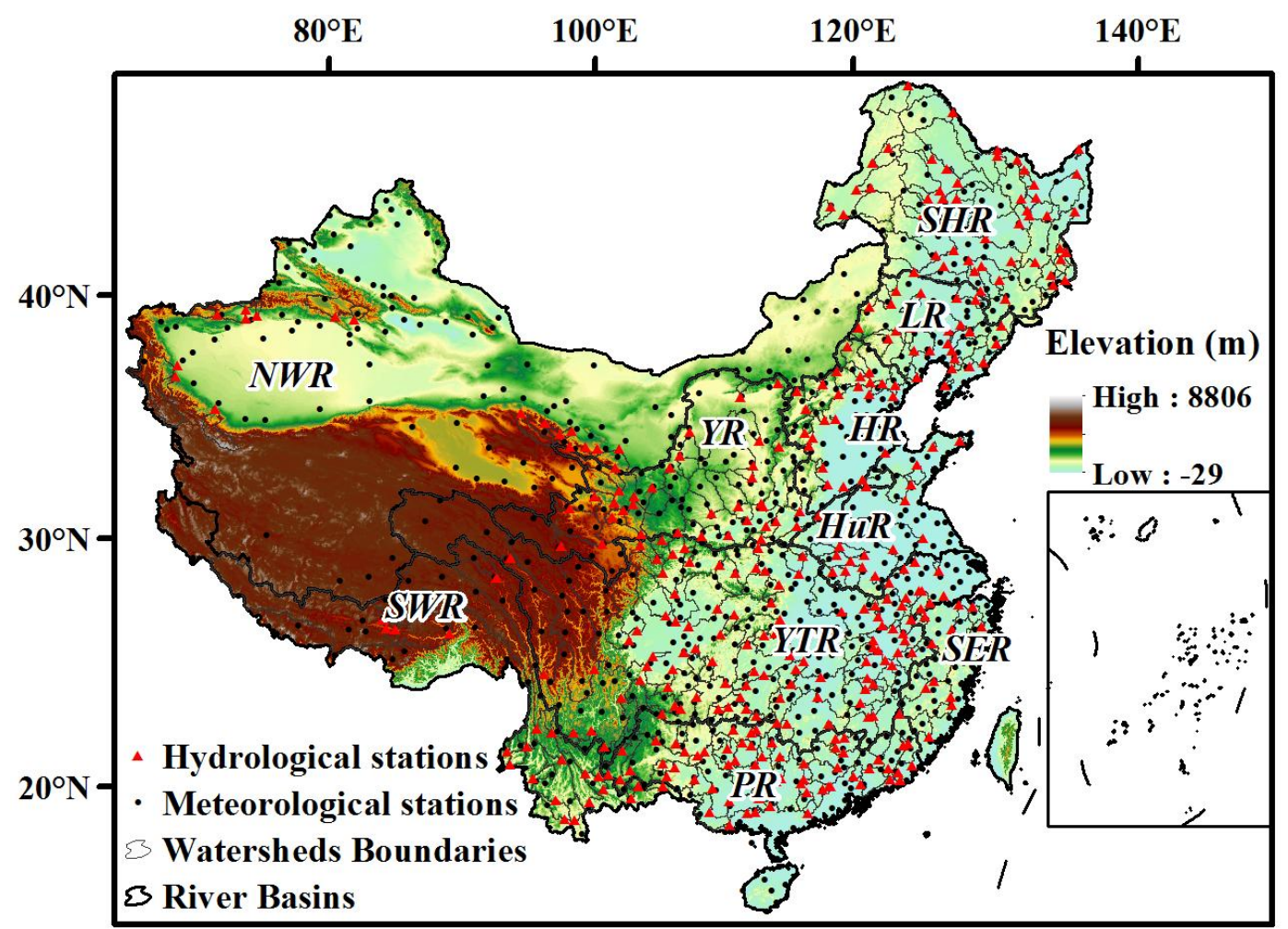

868 Fig. 1 Locations of meteorological and hydrological stations in China. Ten river 869 basins considered in this study are: Songhua River basin (SHR), Liao River basin 870 (LR), Hai River basin (HR), Huai River basin (HuR), Yangtze River basin (YZR), 871 Yellow River basin (YR), Pearl River basin (PR), Southeast Rivers (SER), 872 Southwest Rivers (SWR) and Northwest Rivers (NWR). 

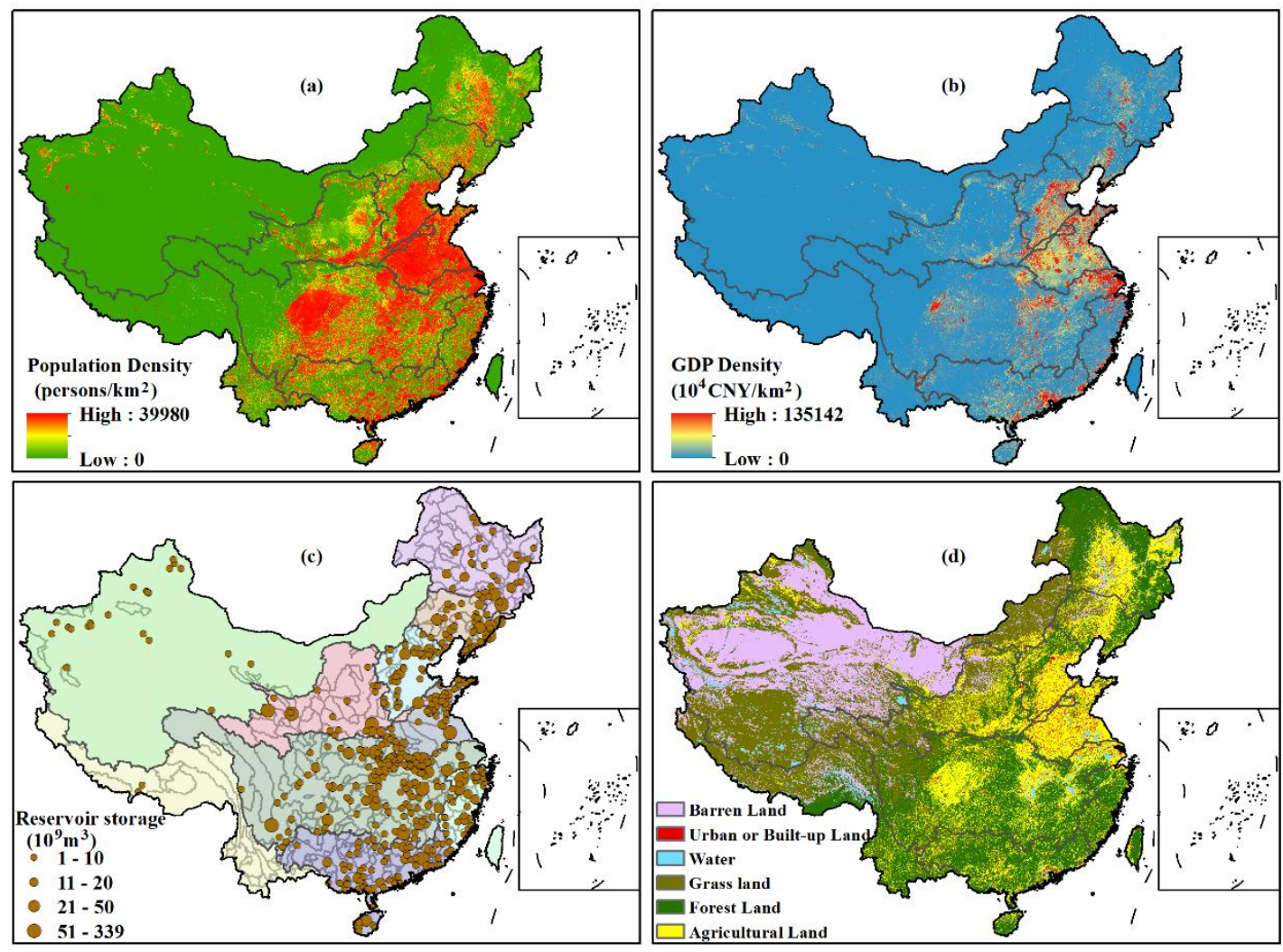

875 Fig. 2 Spatial distribution of GDP population, reservoir storage and land use changes 876 across China, which are used in this study for validation of direct human impacts on mean annual streamflow changes. 


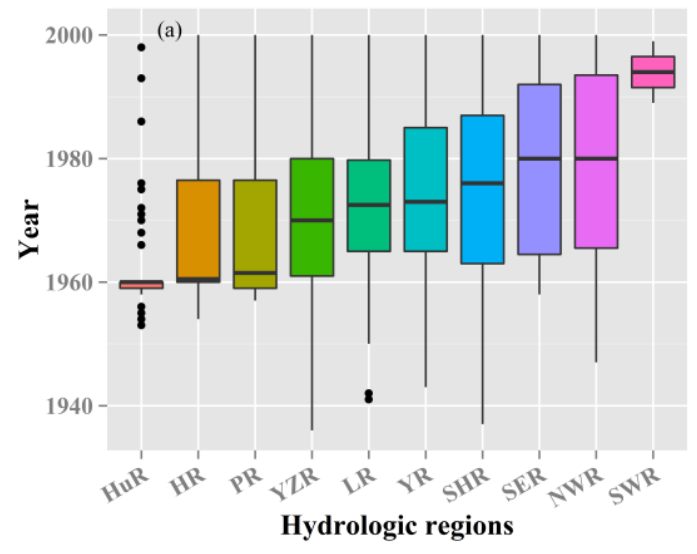

881

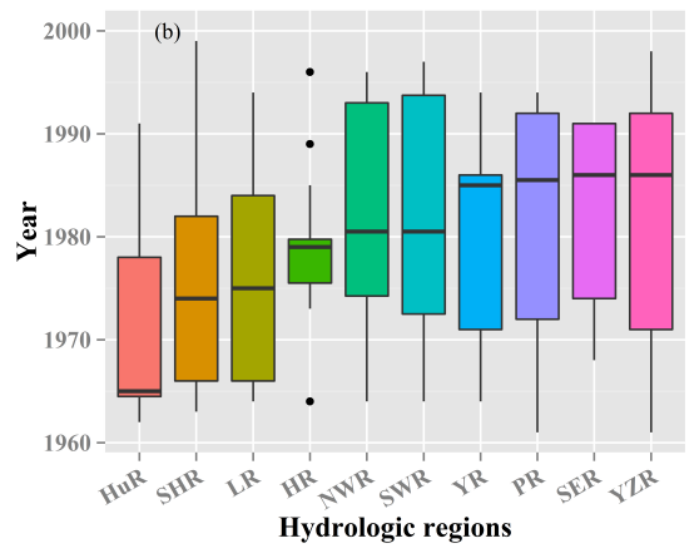

882 Fig. 3 Construction time of large reservoirs (Fig.3a) and change-points of annual 883 streamflow series (Fig.3b) in 10 river basins in China

884 

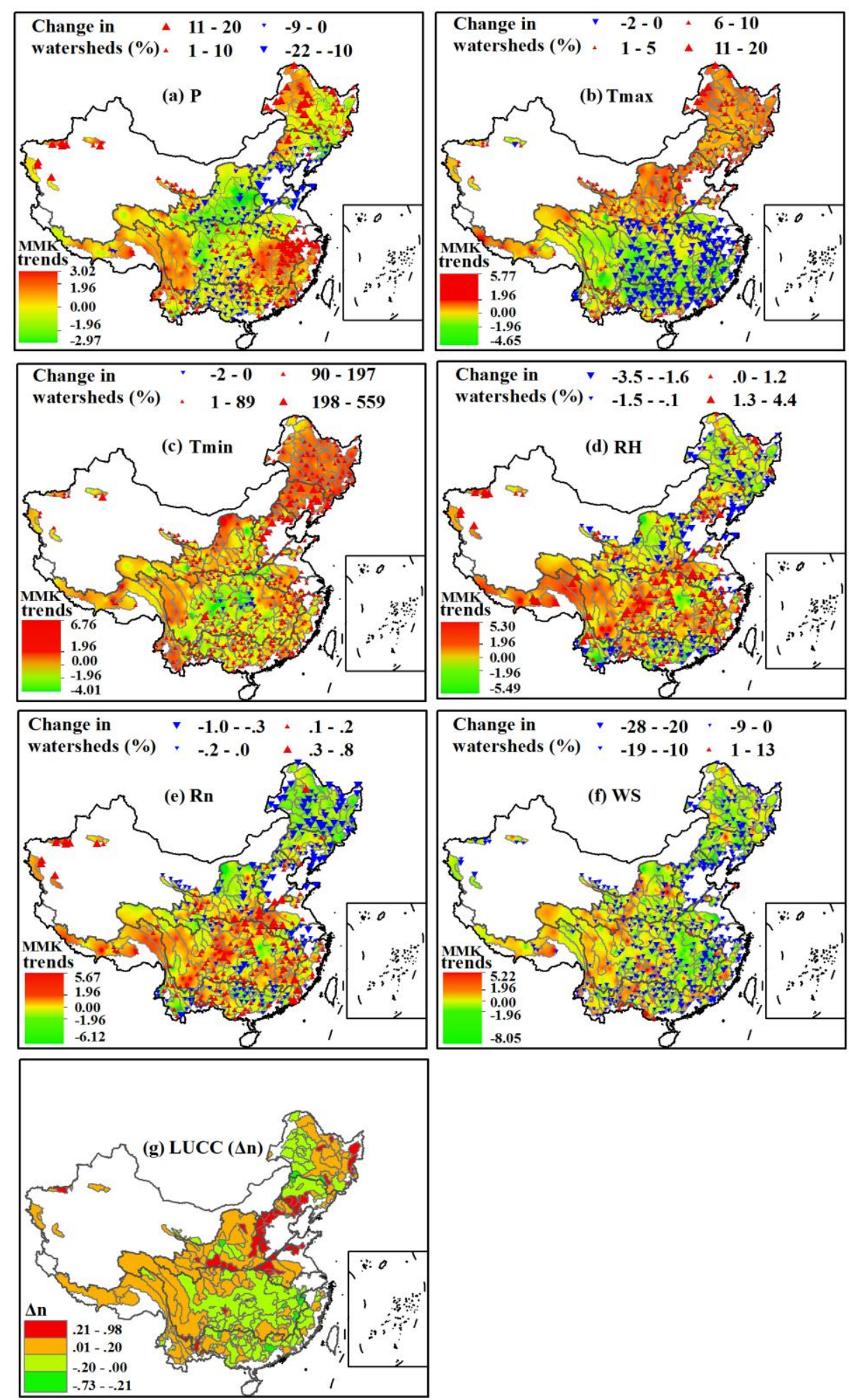

Fig. 4 Spatial distribution of trends (shaded areas) in (a) annual precipitation amount, (b) maximum temperature, (c) minimum temperature, (d) relative humidity, (e) solar radiation, and (f) wind speed. Triangles denote changing rate of above-mentioned meteor-hydrological variables during 1980-2000 relative to those during 1960-1979 at 372 hydrological stations. Fig. 4(g) shows relative changes of $n$ during 1980-2000 relative to those during 1960-1979. 

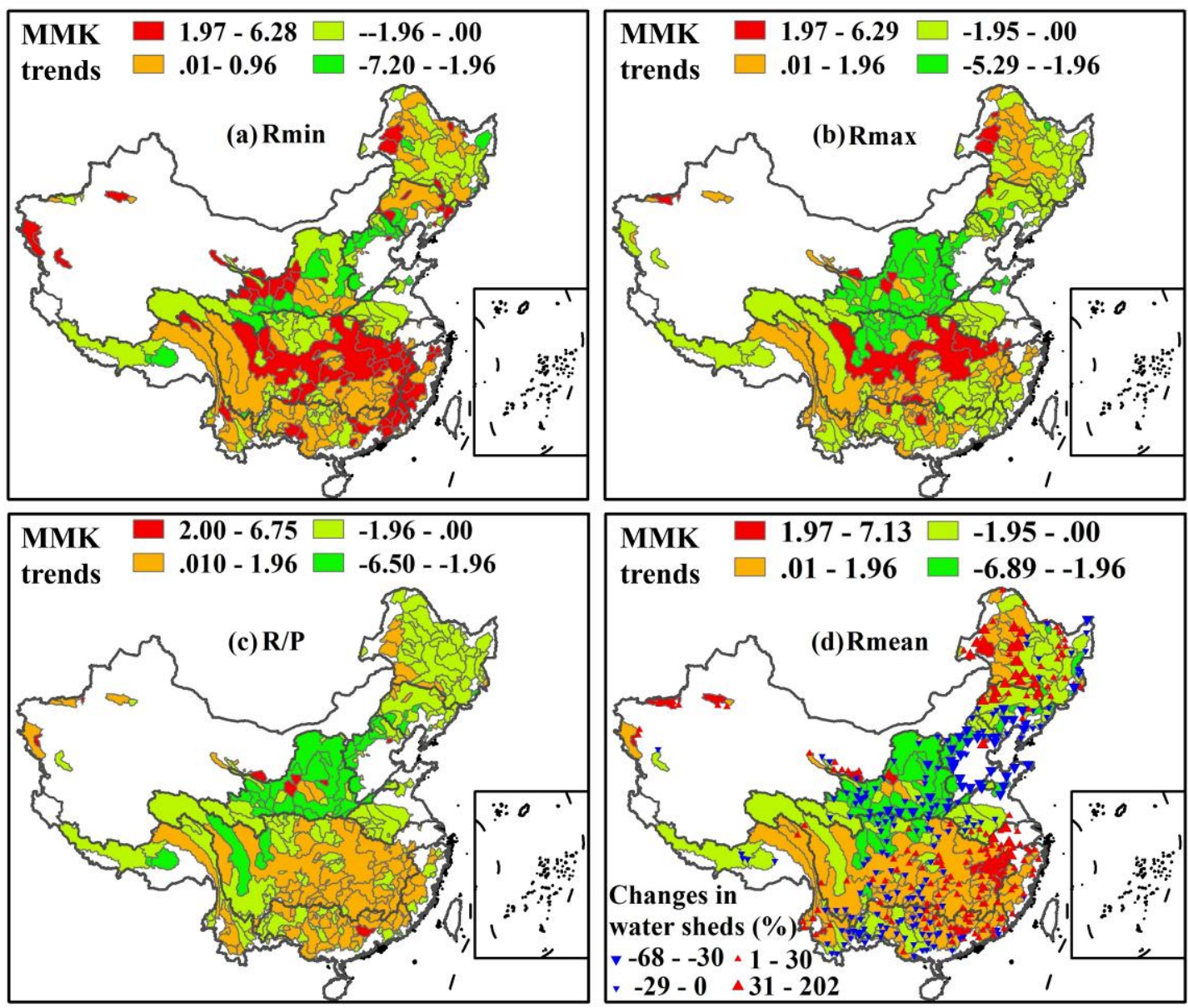

Fig. 5 Spatial distribution of trends (shaded areas) in (a) monthly minimum streamflow, (b) monthly maximum streamflow, (c) streamflow coefficient, (d) annual streamflow. Triangles in Fig. 5(d) denote changing rate of streamflow during 1980-2000 relative to those during 1960-1979 at 372 hydrological stations. 


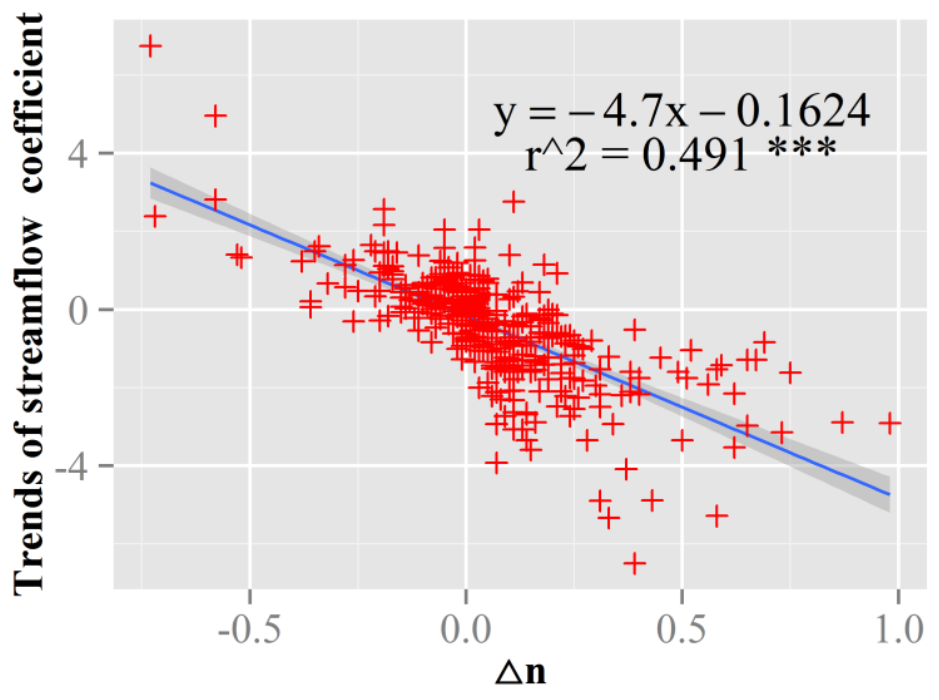

899

900 Fig. 6 Relationships between relative changes of $n$ during 1980-2000 relative to 901 those during 1960-1979 and the trends of runoff coefficient in 372 watersheds during 902 1960-2000.

903

904 

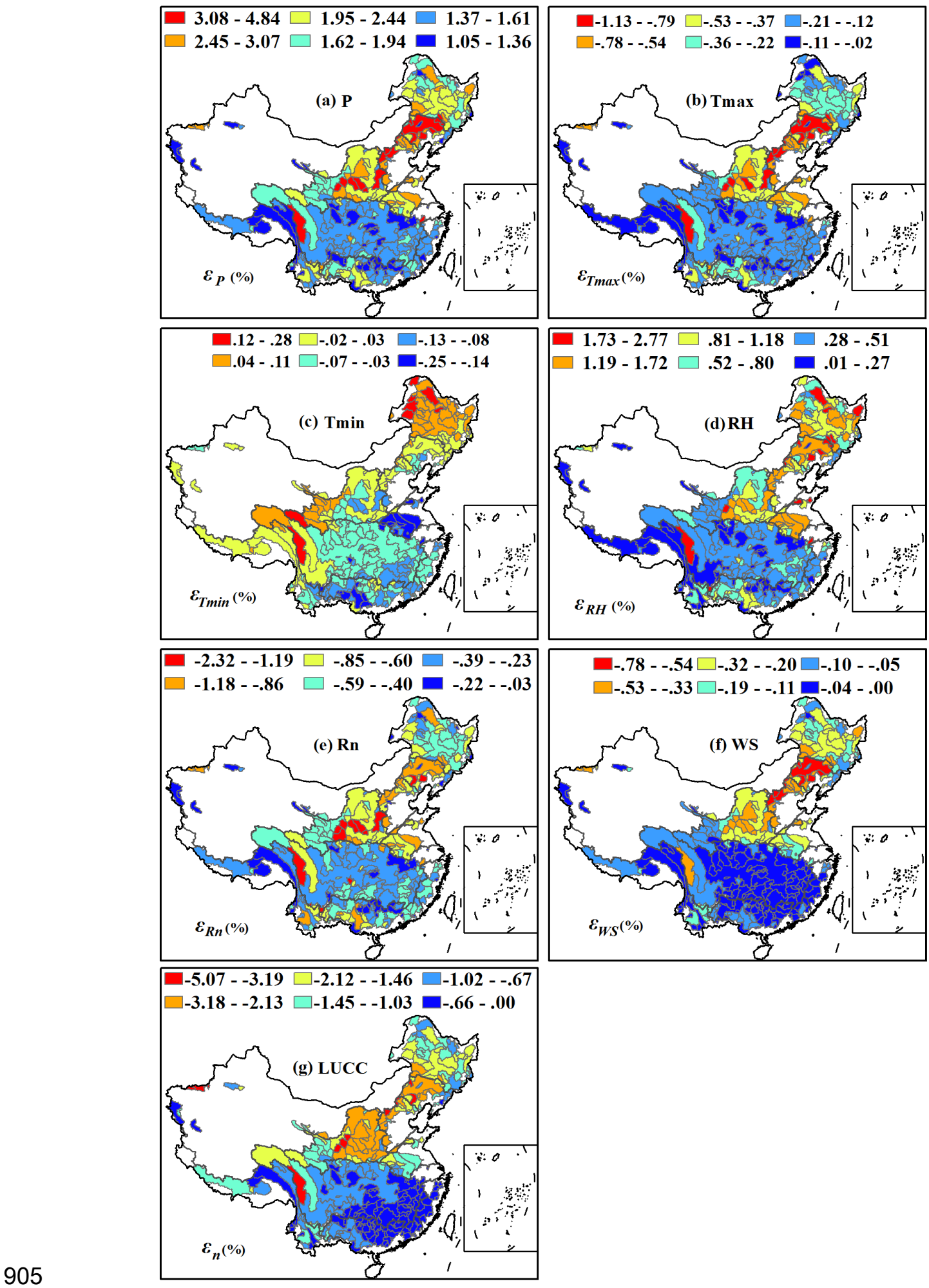

Fig. 7 Spatial distribution of elasticity coefficients of streamflow changes relative to changes in meteor-hydrological variables such as (a) annual precipitation, (b) maximum temperature, (c) minimum temperature, (d) relative humidity, (e) solar radiation, (f) wind speed, and (g) landscape changes. Elasticity in this study is the measurement of how responsive streamflow changes are to a change in a specific meteor-hydrological variable $(\%)$. 


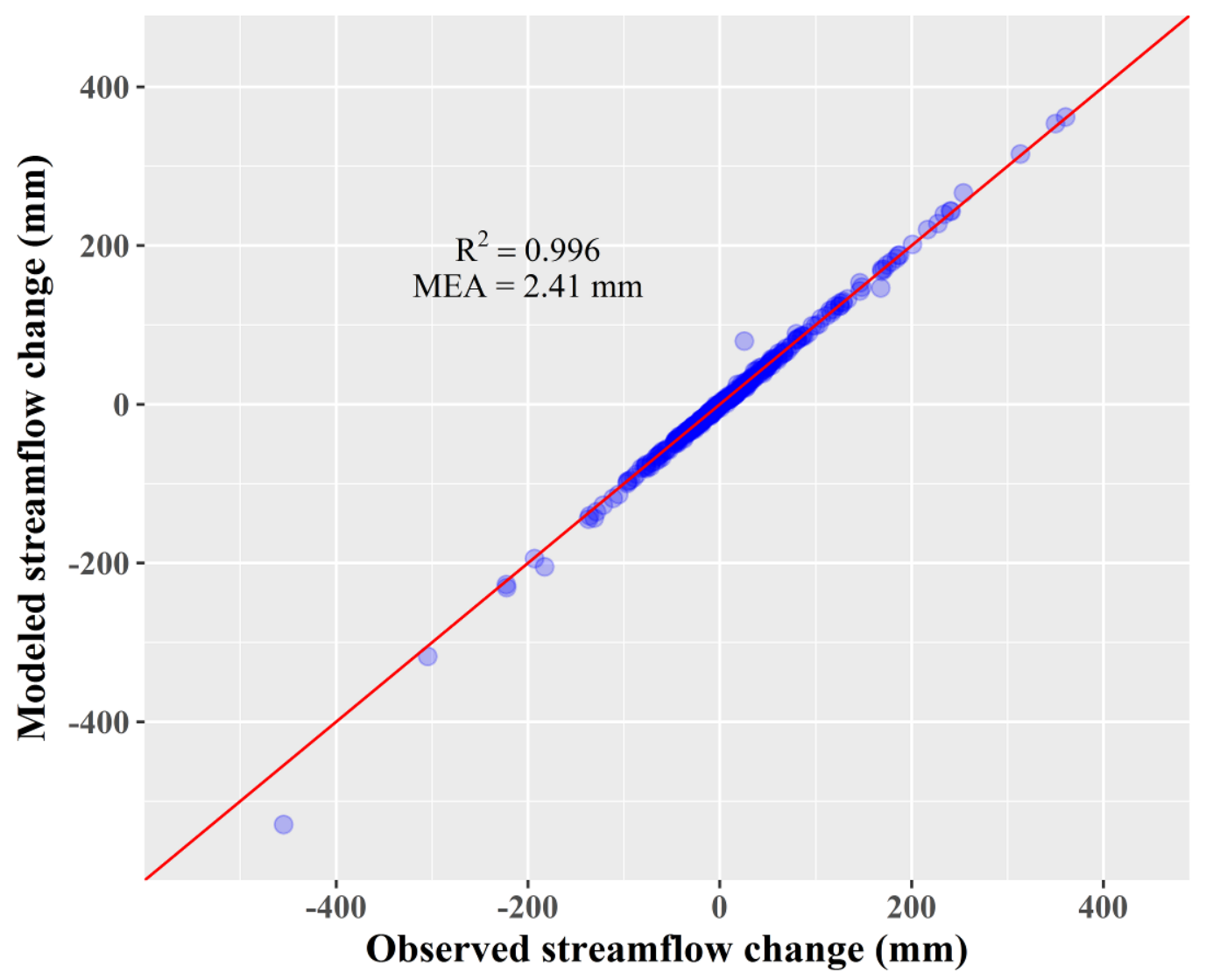

913

914

915

916

917

918

919

920

Fig. 8 Comparison between modeled streamflow change as a result of impacts of meteor-hydrological variables considered in this study, i.e. $\Delta R_{P}+\Delta R_{n}$ $+\Delta R_{R n}+\Delta R_{\text {Tmax }}+\Delta R_{\text {Tmin }}+\Delta R_{U 2}+\Delta R_{R H}$, and the observed changes in streamflow. The straight line is a $1: 1$ straight line. 

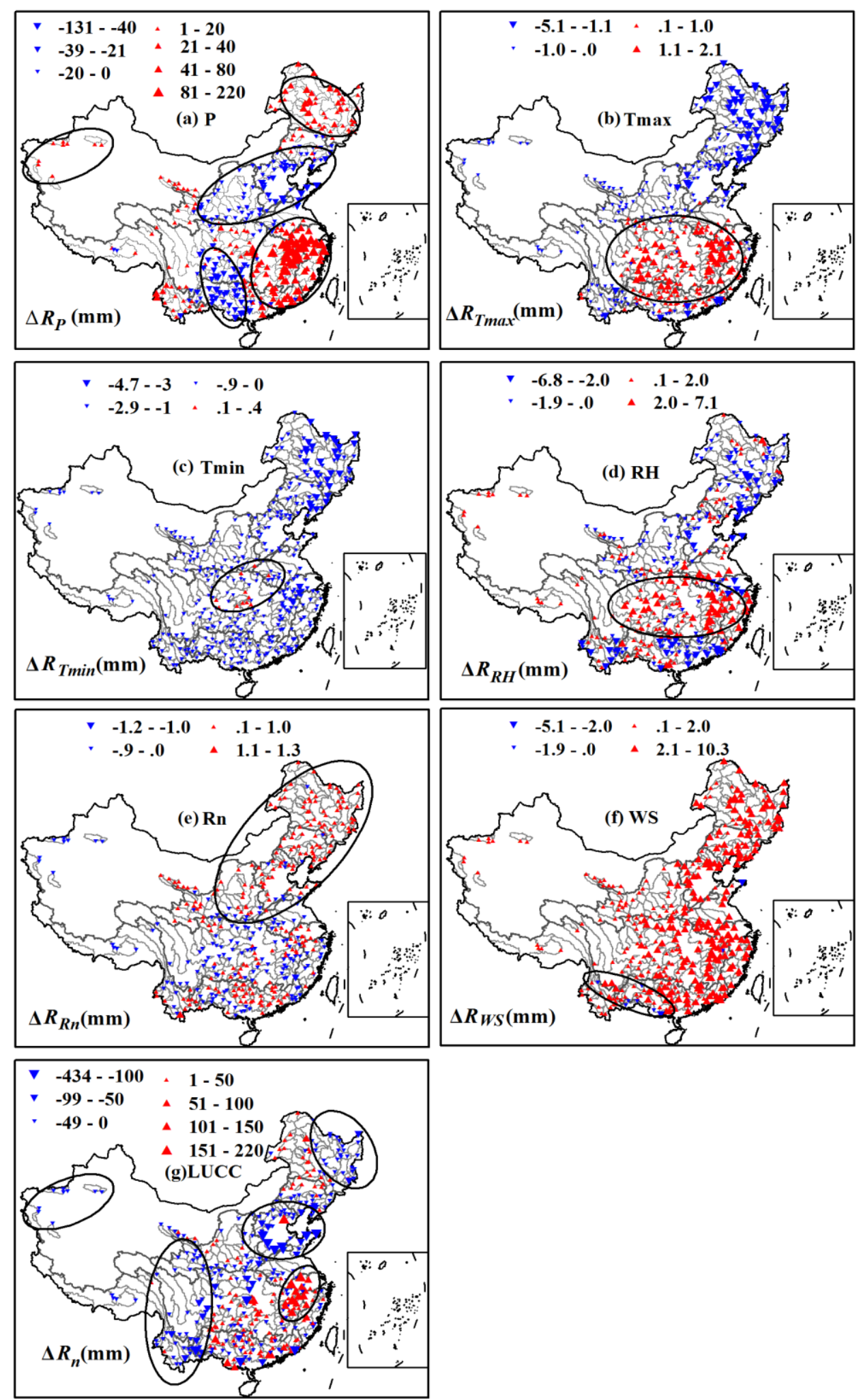

Fig. 9 Spatial distribution of absolute changes in streamflow changes during 1980-2000 relative to those during 1960-1979 due to impacts of specific meteor-hydrological variables (unit: $\mathrm{mm}$ ) at 372 hydrological stations, i.e. (a) annual precipitation, (b) maximum temperature, (c) minimum temperature, (d) relative humidity, (e) solar radiation, (f) wind speed, and (g) landscape parameter $n$. 

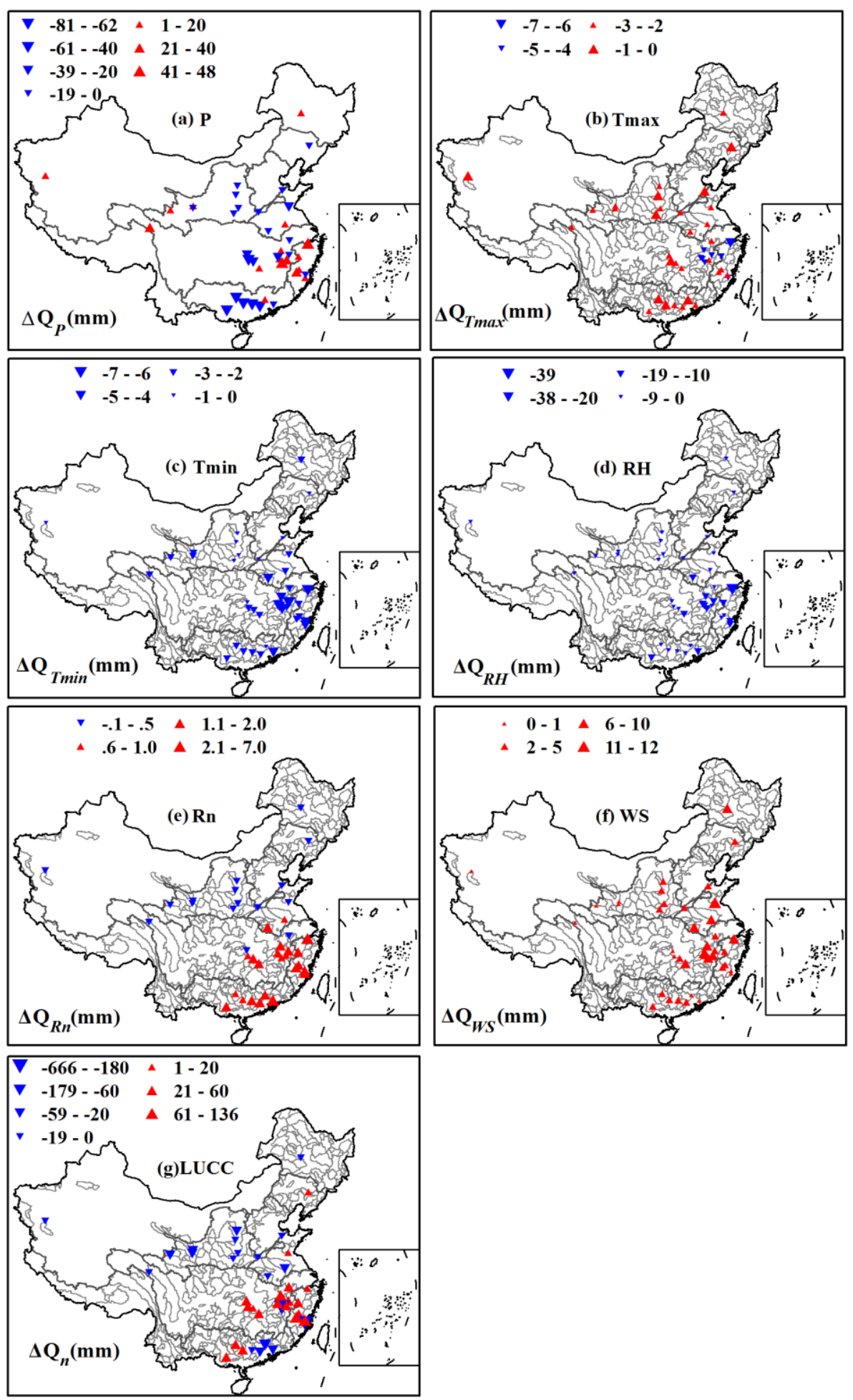

Fig. 10 Spatial distribution of absolute changes in streamflow changes during 2001-2014 relative to those during 1960-1979 due to impacts of specific meteor-hydrological variables (unit: $\mathrm{mm}$ ) at 41 hydrological stations, i.e. (a) annual precipitation, (b) maximum temperature, (c) minimum temperature, (d) relative humidity, (e) solar radiation, (f) wind speed, and (g) landscape parameter $n$. 


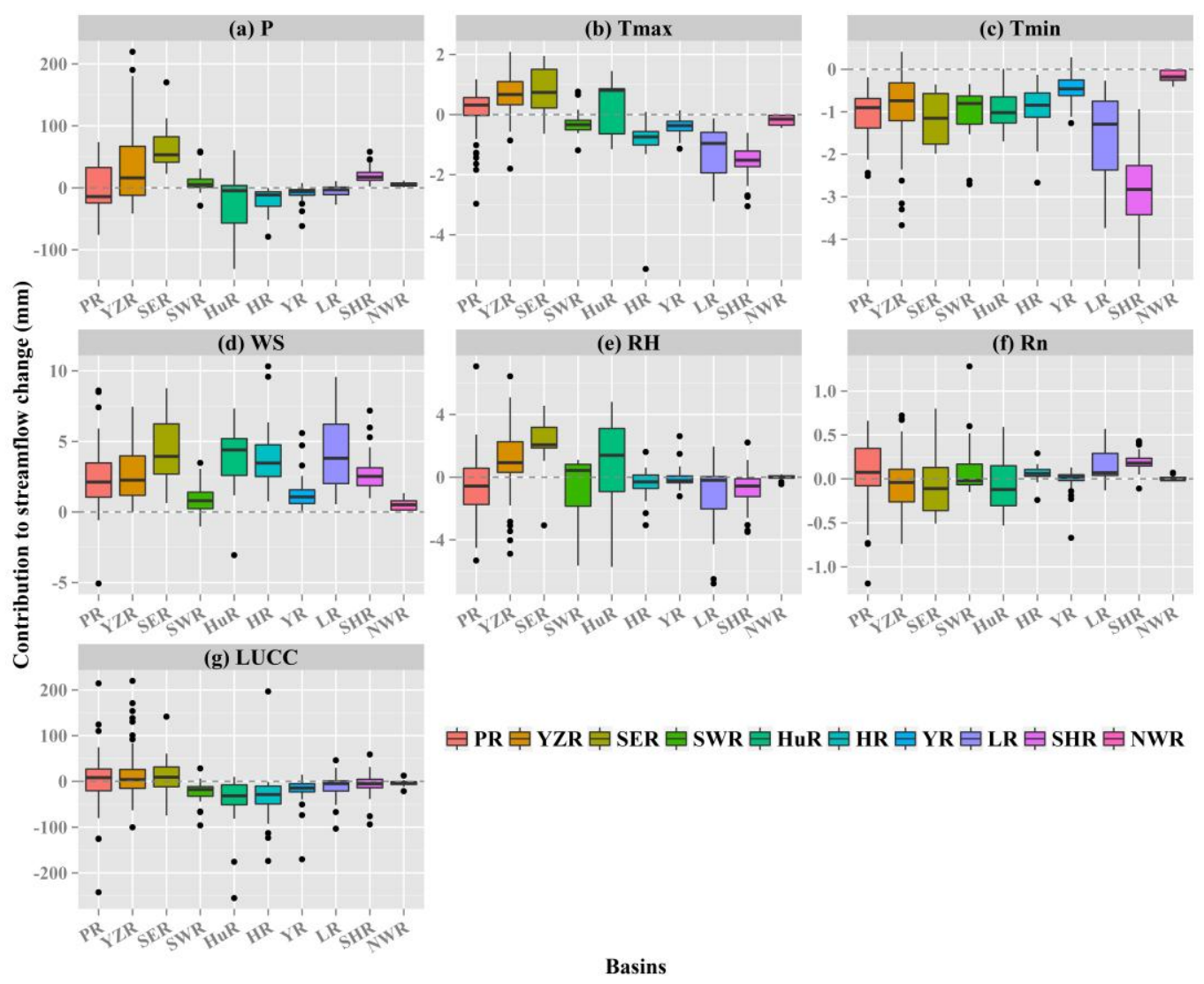

934

935

936

937

938

939

940

941

942

943

944

945

946

947

948 

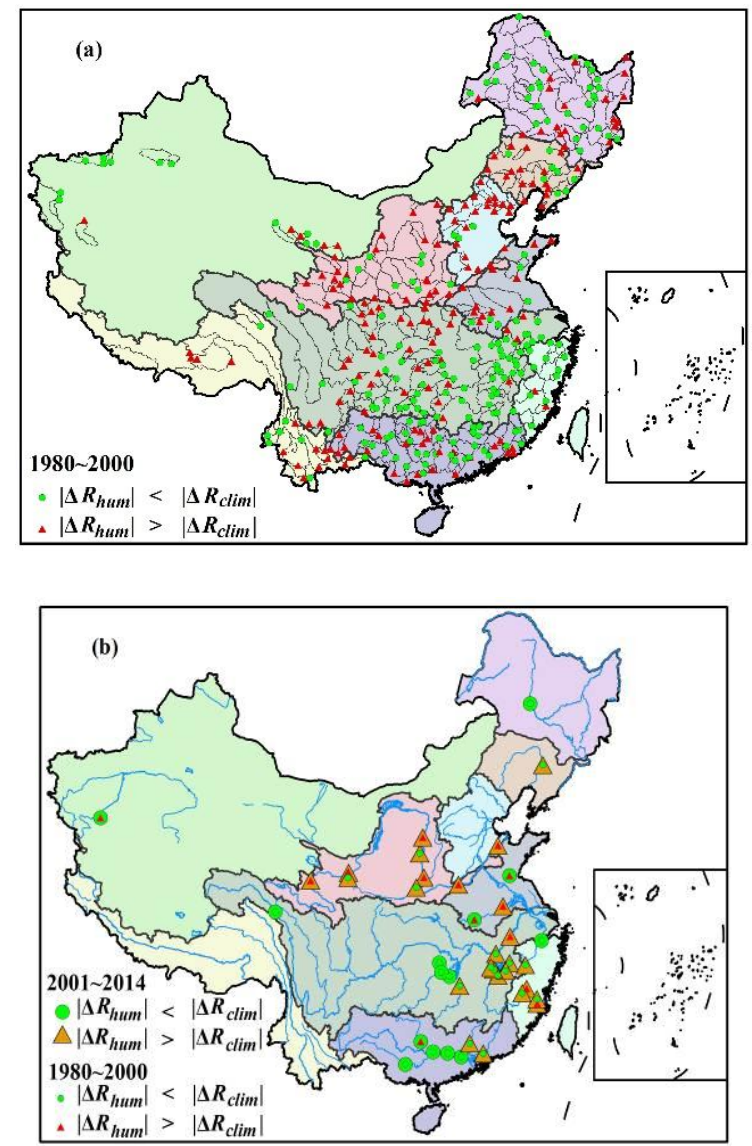

Fig. 12 Spatial distribution of relative fractional contribution of human activities and climate changes to streamflow changes across China. Filled circles denote that climate changes act as the dominant factor influencing streamflow changes, and filled triangles denote that human activities play the key role in influencing streamflow changes. Fig. 12(a) shows spatial distribution of the key influencing factors for streamflow changes during 1980-2000 relative to those during 1960-1979 at 372 hydrological stations; Fig. 12(b) illustrates spatial distribution of the key influencing factors for streamflow changes during 2000-2014 relative to those during 1960-1979 at 41 hydrological stations. For the sake of comparison, the key influencing factors contributing streamflow changes during 1980-2000 relative to those during 1960-1979 are also in Fig. 12(b).

962 

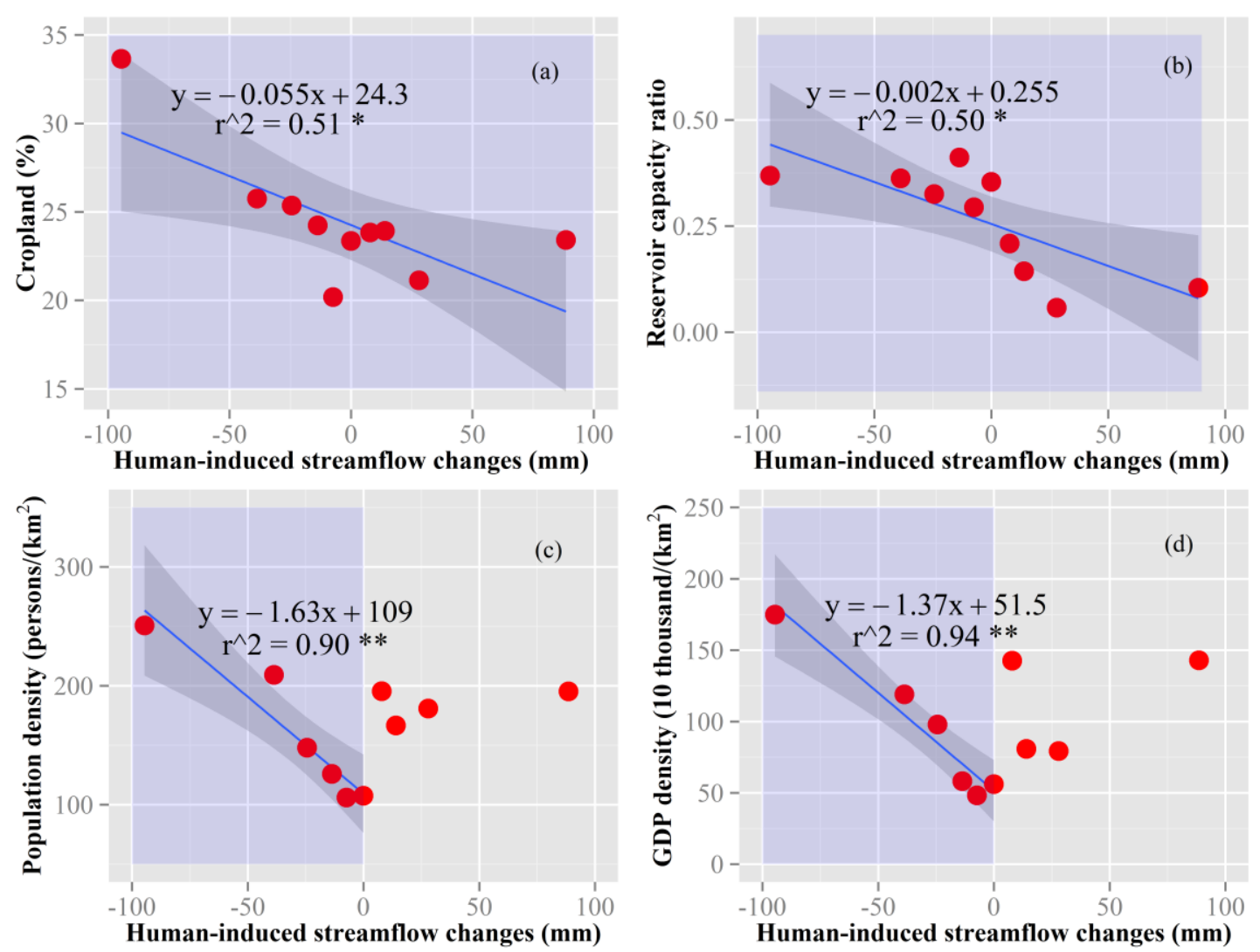

965 Fig. 13 Relationships between human-induced streamflow changes and streamflow changes due to specific human activity. Light blue shadow represents the data field

967 for the regression analysis. 372 river sub-basins are classified into ten groups of river

968 basins based on relative fractional contribution of human activities to streamflow 969 changes. Comparison is done on mean human contribution to streamflow changes in 970 each individual river sub-basin and mean human activity parameter of each river 971 sub-basin. Four human activity variables are considered in this study, i.e. (a) 972 cropland, (b) reservoir storage, (c) population density, and (d) GDP density. 973 Reservoir capacity ratio is the ratio of total capacity in the whole watershed and 974 annual streamflow. 
Table 1 The average of Hydroclimatic variables in 10 river basins across China.

\begin{tabular}{|c|c|c|c|c|c|c|c|c|c|}
\hline Basin & $\begin{array}{c}\text { Area } \\
\left(10^{4} \mathrm{~km}^{3}\right. \\
)\end{array}$ & $\begin{array}{c}\mathrm{P} \\
(\mathrm{mm} \\
)\end{array}$ & $\begin{array}{c}\mathrm{E}_{0} \\
(\mathrm{~mm} \\
)\end{array}$ & $\begin{array}{l}\mathrm{T}_{\max } \\
\left({ }^{\circ} \mathrm{C}\right)\end{array}$ & $\begin{array}{c}\mathrm{T}_{\mathrm{mi}} \\
\mathrm{n} \\
\left({ }^{\circ} \mathrm{C}\right. \\
)\end{array}$ & $\begin{array}{l}\text { RH } \\
(\%)\end{array}$ & $\begin{array}{c}\mathrm{Rn} \\
\left(\mathrm{MJ} /\left(\mathrm{m}^{2} \cdot \text { day }\right.\right. \\
))\end{array}$ & $\begin{array}{l}\mathrm{WS} \\
(\mathrm{m} / \mathrm{s} \\
)\end{array}$ & $\begin{array}{c}\text { Runoff } \\
\text { depth } \\
\text { (mm) }\end{array}$ \\
\hline HR & 30.0 & 507 & 1020 & 14.4 & 1.9 & $\begin{array}{c}58 . \\
1\end{array}$ & 7.9 & 2.8 & 136 \\
\hline HuR & 31.8 & 889 & 1098 & 19.3 & 9.8 & $\begin{array}{c}71 . \\
4\end{array}$ & 8.9 & 2.8 & 277 \\
\hline LR & 29.3 & 581 & 991 & 13.3 & 1.2 & $\begin{array}{c}59 \\
8\end{array}$ & 7.5 & 2.8 & 140 \\
\hline NWR & 316.8 & 198 & 1036 & 13.1 & -1.2 & $\begin{array}{c}51 . \\
7\end{array}$ & 8.0 & 2.2 & 81 \\
\hline PR & 57.8 & 1512 & 1205 & 24.1 & $\begin{array}{c}15 \\
6\end{array}$ & $\begin{array}{c}78 \\
7\end{array}$ & 10.4 & 1.8 & 838 \\
\hline SER & 20.1 & 1597 & 1105 & 22.6 & $\begin{array}{c}13 \\
7\end{array}$ & $\begin{array}{c}79 . \\
5\end{array}$ & 10.0 & 2.0 & 902 \\
\hline SHR & 85.3 & 523 & 811 & 8.7 & -4.1 & $\begin{array}{c}66 . \\
0\end{array}$ & 6.9 & 2.9 & 145 \\
\hline SWR & 86.1 & 913 & 1152 & 18.9 & 6.6 & $\begin{array}{c}66 . \\
7\end{array}$ & 10.0 & 2.0 & 453 \\
\hline YR & 75.7 & 490 & 997 & 13.3 & 0.5 & $\begin{array}{c}60 \\
4\end{array}$ & 8.6 & 2.4 & 111 \\
\hline YZR & 178.3 & 1236 & 1071 & 19.9 & $\begin{array}{c}10 \\
9\end{array}$ & $\begin{array}{c}76 . \\
4\end{array}$ & 9.7 & 1.9 & 644 \\
\hline
\end{tabular}


978 Table 2 The average contributions of different factors to streamflow changes in 10 979 river basins across China. The factors are: precipitation (P), parameter $n$ of LUCC 980 (LUCC), maximum temperatures $\left(\mathrm{T}_{\max }\right)$; minimum temperatures $\left(\mathrm{T}_{\min }\right)$; wind speed 981 (WS); relative humidity $(\mathrm{RH})$ and solar radiation $\left(\mathrm{R}_{\mathrm{n}}\right)$.

\begin{tabular}{llllllll}
\hline $\begin{array}{l}\text { River } \\
\text { basins }\end{array}$ & $\mathrm{P}$ & LUCC & Tmax & Tmin & WS & RH & Rn \\
\hline PR & -0.9 & 0.7 & 0.1 & -1.1 & 2.4 & -0.7 & 0.06 \\
YZR & 34.5 & 10.5 & 0.7 & -0.8 & 2.7 & 1.1 & -0.05 \\
SER & 67.1 & 13.7 & 0.8 & -1.2 & 4.2 & 2.1 & -0.08 \\
SWR & 9.7 & -23.3 & -0.3 & -1.0 & 0.9 & -0.4 & 0.13 \\
HuR & -22.7 & -62.1 & 0.3 & -0.9 & 3.7 & 0.9 & -0.08 \\
HR & -19.4 & -32.8 & -1.0 & -0.9 & 4.0 & -0.4 & 0.06 \\
YR & -9.6 & -19.4 & -0.4 & -0.5 & 1.4 & -0.1 & -0.01 \\
LR & -5.4 & -11.8 & -1.2 & -1.7 & 4.1 & -1.2 & 0.15 \\
SHR & 19.3 & -6.0 & -1.6 & -2.8 & 2.7 & -0.7 & 0.20 \\
NWR & 5.8 & -3.5 & -0.2 & -0.2 & 0.5 & 0.0 & 0.01 \\
China & 12.1 & -6.0 & -0.17 & -1.2 & 2.55 & 0.1 & 0.04 \\
\hline
\end{tabular}

982

983 
Table 3 Fractional contribution of climate changes and human activities to 985 streamflow changes during the period 2 (1980-2000) and period 3 (2001-2014) related to the 986 period 1 (1960-1979) within 10 large river basins considered in this study.

\begin{tabular}{|c|c|c|c|c|c|c|c|}
\hline Basin & Periods & $\begin{array}{l}\Delta \mathrm{R} \\
(\mathrm{mm})\end{array}$ & $\begin{array}{l}\text { Clima } \\
\mathrm{d} \\
\mathrm{mm}\end{array}$ & -induce & $\begin{array}{l}\text { Huma } \\
\mathrm{d} \\
\mathrm{mm}\end{array}$ & induce & $\begin{array}{l}\text { No. of stations } \\
\text { dominated by } \\
\text { Climate/Human }\end{array}$ \\
\hline \multirow{2}{*}{ PR } & period-2 & 1.2 & 0.5 & 40.6 & 0.7 & 59.4 & $36 / 26$ \\
\hline & period-3 & -65.9 & -62.3 & 92.0 & -5.4 & 8.0 & $5 / 2$ \\
\hline \multirow{2}{*}{ YZR } & period-2 & 49.5 & 38.6 & 78.7 & 10.5 & 21.3 & $65 / 40$ \\
\hline & period-3 & -29.4 & -11.6 & 39.1 & -18.0 & 60.9 & $5 / 8$ \\
\hline \multirow{2}{*}{ SER } & period-2 & 87.7 & 73.3 & 84.2 & 13.7 & 15.8 & $11 / 2$ \\
\hline & period-3 & 65.7 & 10.0 & 15.2 & 55.8 & 84.8 & $1 / 5$ \\
\hline \multirow{2}{*}{ SWR } & period-2 & -13.3 & 9.8 & 29.6 & -23.3 & 70.4 & $8 / 14$ \\
\hline & period-3 & - & - & - & - & - & - \\
\hline \multirow{2}{*}{ HuR } & period-2 & -73.7 & -18.3 & 22.7 & -62.1 & 77.3 & $6 / 9$ \\
\hline & period-3 & -16.0 & -10.9 & 67.8 & -5.2 & 32.2 & $2 / 1$ \\
\hline \multirow{2}{*}{ HR } & period-2 & -47.4 & -16.8 & 33.8 & -32.8 & 66.2 & $3 / 19$ \\
\hline & period-3 & - & - & - & - & - & - \\
\hline \multirow{2}{*}{ YR } & period-2 & -27.3 & -8.4 & 30.3 & -19.4 & 69.7 & $10 / 28$ \\
\hline & period-3 & -27.5 & -4.8 & 16.9 & -23.5 & 83.1 & $0 / 9$ \\
\hline \multirow{2}{*}{ LR } & period-2 & -15.3 & -3.9 & 24.7 & -11.8 & 75.3 & $8 / 17$ \\
\hline & period-3 & 2.9 & -6.3 & 41.1 & 9.0 & 58.9 & $0 / 1$ \\
\hline \multirow{2}{*}{ SHR } & period-2 & 14.1 & 20.0 & 76.9 & -6.0 & 23.1 & $33 / 19$ \\
\hline & period-3 & 3.8 & 7.3 & 68.4 & -3.4 & 31.6 & $1 / 0$ \\
\hline \multirow{2}{*}{ NWR } & period-2 & 3.2 & 6.6 & 65.7 & -3.5 & 34.3 & $12 / 6$ \\
\hline & period-3 & 9.2 & 14.8 & 72.2 & -5.7 & 27.8 & $1 / 0$ \\
\hline \multirow{2}{*}{ China } & period-2 & 8.9 & 14.4 & 71.0 & -6.0 & 29.0 & $192 / 180$ \\
\hline & period-3 & -23.4 & -12.9 & 53.5 & -11.2 & 46.5 & $15 / 26$ \\
\hline
\end{tabular}


Table 4 Comparative studies of fractional contribution of climatic changes and human activities to streamflow changes.

\begin{tabular}{|c|c|c|c|c|c|c|c|}
\hline Basin & Catchment & $\begin{array}{l}\text { Number of } \\
\text { stations }\end{array}$ & $\begin{array}{l}\text { Study } \\
\text { period }\end{array}$ & Method/model & $\delta$ Rclim. & \&Rhum. & Sources \\
\hline PR & East River & 3 & $1956-2000$ & $\begin{array}{l}\text { Back-propagation artificial } \\
\text { neural network (BP-ANN) }\end{array}$ & $46.8 \%$ & $53.2 \%$ & Liu et al., 2010 \\
\hline \multirow[t]{2}{*}{ YZR } & Yangtze River & 4 & $1953-2010$ & Linear regression & $72 \%$ & $28 \%$ & Zhao et al., 2015 \\
\hline & $\begin{array}{l}\text { Poyang Lake } \\
\text { basin }\end{array}$ & 5 & $1955-2009$ & $\begin{array}{l}\text { Australia Water Balance } \\
\text { Model; Sensitivity analysis }\end{array}$ & $72.1 \%$ & $27.9 \%$ & Zhang et al., 2016 \\
\hline \multirow[t]{2}{*}{ SWR } & $\begin{array}{l}\text { Yarlung Zangbo } \\
\text { River }\end{array}$ & 4 & $1974-2000$ & Modified double mass curve & $70 \%-77 \%$ & & Liu et al., 2014 \\
\hline & $\begin{array}{l}\text { Lanchang and } \\
\text { Nu Rivers }\end{array}$ & 2 & $1950 s-2010$ & Random forest regression & about $65 \%$ & l & Fan et al., 2015 \\
\hline HuR & $\begin{array}{l}\text { Huaihe River } \\
\text { Basin }\end{array}$ & 14 & $1960-2011$ & $\begin{array}{l}\text { Based on Budyko hypothesis } \\
\text { model }\end{array}$ & $33 \%$ & $67 \%$ & Zhang et al., 2012 \\
\hline \multirow[t]{2}{*}{ HR } & $\begin{array}{l}\text { Haihe River } \\
\text { Basin }\end{array}$ & 33 & $1956-2005$ & $\begin{array}{l}\text { Based on Budyko hypothesis } \\
\text { model }\end{array}$ & $26.90 \%$ & $73.10 \%$ & Xu et al., 2014 \\
\hline & $\begin{array}{l}\text { Luan, Chaobai } \\
\text { and Zhang River }\end{array}$ & 3 & $1957-2000$ & $\begin{array}{l}\text { Hydrological model and } \\
\text { Sensitivity analysis }\end{array}$ & $32.7 \%-41.7 \%$ & $58.3 \%-67.3 \%$ & Wang et al., 2013 \\
\hline \multirow[t]{3}{*}{ YR } & Yellow River & 7 & $1950-2009$ & $\begin{array}{l}\text { Slope change ratio of } \\
\text { cumulative quantity }\end{array}$ & $7.93 \%$ & $92.07 \%$ & Wang et al., 2012 \\
\hline & Yellow River & 14 & $1961-2009$ & $\begin{array}{l}\text { Based on Budyko hypothesis } \\
\text { model }\end{array}$ & $38.0 \%$ & $62.0 \%$ & Liang et al., 2015 \\
\hline & Yellow River & 7 & $1960 s-2008$ & Linear regression & $17.0 \%$ & $23.0 \%$ & Miao et al., 2011 \\
\hline LR & $\begin{array}{l}\text { West Liaohe } \\
\text { River Basin }\end{array}$ & 1 & 1964-2009 & VIC model & $36 \%$ & $64 \%$ & Yang et al., 2014 \\
\hline SHR & $\begin{array}{l}\text { Songhua River } \\
\text { Basin }\end{array}$ & 3 & 1960-2009 & Double cumulative curve & $62 \%-82 \%$ & $63 \%-65 \%$ & Li F et al., 2014 \\
\hline NWR & $\begin{array}{l}\text { Tarim River } \\
\text { Basin }\end{array}$ & 5 & $1957-2008$ & $\begin{array}{l}\text { Periodicity-trend } \\
\text { superposition model }\end{array}$ & $85.2 \%$ & $14.8 \%$ & Ling et al., 2014 \\
\hline
\end{tabular}

